Report Title:

\title{
PARTICLE TRANSPORT AND DEPOSITION IN THE HOT-GAS FILTER AT WILSONVILLE
}

\begin{tabular}{cl}
\hline Report Type: & QUARTERLY Reporting Period Start Date: 1/1/1999 End Date: 3/31/1999 \\
\hline Principal Author(s): & Goodarz Ahmadi \\
& Department of Mechanical and Aeronautical Eng. \\
& Clarkson University \\
& Potsdam, NY 13699-5725
\end{tabular}

\begin{tabular}{ll|ll} 
Report Issue Date: & 06/24/1999 & DOE Award No.: & DE-FC26 - 98FT40447--01
\end{tabular}

Submitting

Organization(s) Clarkson University

Name \& Address Potsdam, NY 13699-5725 


\title{
PARTICLE TRANSPORT AND DEPOSITION IN THE HOT-GAS
}

\author{
FILTER VESSEL AT WILSONVILLE
}

\author{
Haifeng Zhang and Goodarz Ahmadi \\ Department of Mechanical and Aeronautical Engineering \\ Clarkson University, Potsdam, N.Y. 13699 USA
}

\begin{abstract}
:
Particle transport and deposition in the Wilsonville hot-gas filter vessel is studied. The filter vessel contains a total of 72 filters, which are arranged in two tiers. These are modeled by six upper and one lower cylindrical effective filters. An unstructured grid of 312,797 cells generated by GAMBIT is used in the simulations. The Reynolds stress model of FLUENT ${ }^{\mathrm{TM}}$ (version 5.0) code is used for evaluating the gas mean velocities and root mean-square fluctuation velocities in the vessel. The particle equation of motion includes the drag, the gravitational and the lift forces. The turbulent instantaneous fluctuation velocity is simulated by a filtered Gaussian white-noise model provided by the FLUENT code. The particle deposition patterns are evaluated, and the effect of particle size is studied. The effect of turbulent dispersion, the lift force and the gravitational force are analyzed. The results show that the deposition pattern depends on particle size. Turbulent dispersion plays an important role in transport and deposition of particles. Lift and gravitational forces affect the motion of large particles, but has no effect on small particles.
\end{abstract}




\section{INTRODUCTION}

In recent years, considerable effort has been directed toward developing advanced clean coal technology for electric power generation with high efficiency and low pollutants. As part of the Clean Coal Technology Program, advanced pressurized fluidized bed combustion (PFBC) and integrated gasification combined cycles (IGCC) are being developed and tested. These highly efficient advanced coal energy systems require effective removal of ash and unreacted and reacted sulfur sorbent from the hot gases.

The current technology has been focused on the use of ceramic candle filters for hotgas filtration. The candle filters are hollow cylinders (closed on one end) typically with a diameter of about $6 \mathrm{~cm}$ and a length of 1 to $1.5 \mathrm{~m}$. The wall thickness varies between 0.8 to $1.5 \mathrm{~cm}$. An industrial filter vessel normally contains a large number of candle filters. Groups of candle filters are periodically cleaned by a rapid (reverse-flow) pulseback procedure to remove the dust cake that builds up on filter surfaces. A number of hot-gas filtration systems were developed and tested in the past. The Federal Energy Technology Center (FETC) Integrated Gasification and Cleanup Facility (IGCF), which can support four candle filters, was described by Rockey et al. (1995). The IGCF operational data were analyzed by Smith et al. (1997, 1998a, 1998b), where simple models for interpretation of the pressure drop time variation were also presented. The test results on the fullscale hot-gas PFBC filtration system at the Tidd Power Plant in Ohio were reported by Lippert et al. (I 995).

The Advanced Particle Filter (APF), designed by Westinghouse, was installed at the $70 \mathrm{MW}$ (electric) Tidd PFBC Demonstration Plant at Brilliant, Ohio, in 1992. The operation of the Tidd 
hot-gas filtration system was described by Mudd and Hoffman (1993, 1994). The test results on the Tidd hot-gas filtration system were reported by Lippert et al. (1993, 1994, 1995). The composition and chemistry of particles in the Tidd filter vessel were studied by Southern Research Institute (1993), Pontius (1995), Hurley (1995), Chiang (1996), and Smith et al. (1997b)

An extensive reviews of gas cleanup at high temperatures, including candle filters, was provided by Thambimuthu (1993). The candle filters generally have a very high cleaning efficiency of the order of $99.8 \%$. There are, however a number of unresolved problems with buildup of dust cake on the filters, occasional filter-ash bridging and filter failure and breakage.

A fundamental understanding of the particle transport and deposition processes in the filter vessels is needed to improve the effectiveness and reliability of hot-gas filtration systems. There have been considerable research efforts on the mechanisms that control dispersion and deposition of aerosol particles. During the turbulent gas motion, the particles are convected by the mean motion and are dispersed by the fluctuating velocities. Semi-empirical expressions for particle mass flux from a turbulent stream to surfaces were developed by Friedlander and Johnstone (195 7), Cleaver and Yates (1975), Wood (1981a, b), Hinds (1982), Hidy (1984), and Papavergos and Hedley (1984). Li and Ahmadi and co-workers (1993, 1994, 1995) developed a computational model for simulating turbulent deposition of aerosols in complex passages. Ahmadi and Smith (1997) described the results of their computer simulations on the deposition of particles in the experimental FETC Integrated Gasification and Cleanup Facility (IGCF). The stress transport model of FLUENT ${ }^{\mathrm{TM}}$ code is used by Ahmadi and Smith (1998a) to evaluate the gas mean velocity and the root mean-square fluctuation velocity fields in the IGCF filter vessel. Ahmadi and Smith (1998b) describes a computer simulation study of gas flow and particle deposition in the hot-gas 
filter vessel at Tidd 70 MWE PFBC Demonstration Power Plant.

In this work, particle transport and deposition in the hot-gas filter vessel at Wilsonville, Alabama is studied. The Reynolds stress model of FLUENT ${ }^{\mathrm{TM}}$ (version 5.0) code is used for evaluating the gas mean velocity and root mean-square fluctuation velocity in the filter system. The particle equation of motion includes the drag, the gravitational and the lift forces. The turbulent instantaneous fluctuation velocity is simulated by a filtered Gaussian white-noise model provided by the FLUENT ${ }^{\mathrm{TM}}$ code. The particle deposition patterns are evaluated, and the effect of particle size is studied. The results show that the deposition rates on different surfaces depend on particle size. Turbulence plays an important role on particle dispersion and deposition processes. Lift and gravitational force affect the transport of large particles.

\section{WILSONVILLE HOT-GAS FILTER VESSEL}

The hot-gas filter vessel at Wilsonville, Alabama has a diameter of $1.6 \mathrm{~m}$ (63 in) and a height of $8.27 \mathrm{~m}$ (325.7 in). The vessel accommodates 72 candle filters arranged in two clusters. The upper and lower tiers each have 36 candle filters. The $1.5 \mathrm{~m}(4.92 \mathrm{ft})$ long ceramic candle filters have an outer diameter of $6 \mathrm{~cm}$ (2.36 in). An important feature if the Wilsonville hot-gas filtration system is that the gas enters the vessel tangentially into the shroud. The shroud is also comparatively large and cylindrical in shape. The geometry of the filter vessel is shown in Figure 1.

The average gas mass flow rate to the filter vessel is $2.95 \mathrm{~kg} / \mathrm{s}(23,500 \mathrm{lb} / \mathrm{hr})$. The filter vessel operating pressure is $1344 \mathrm{kPa}(195 \mathrm{psia})$, and-the design operating temperature is $1033 \mathrm{~K}$. The corresponding filter vessel inlet flow velocity is $9.815 \mathrm{~m} / \mathrm{s}$, the density of air is $4.53 \mathrm{k} \mathrm{g} / \mathrm{M}^{3}$ and the viscosity of air is $3.7 \times 10^{-5} \mathrm{~kg} / \mathrm{ms}$. 
In the present simulations, the group of filters in the upper tier is modeled by six effective cylindrical filters of radius $14.1 \mathrm{~cm}$ and wall thickness of 1.8 , and the lower cluster of filters is replaced by an effective large cylindrical filter with an outer radius of $46.1 \mathrm{~cm}$ and an inner radius of $27.9 \mathrm{~cm}$ as shown in Figure 2. The effective permeability of each equivalent filter is selected in such a way that the effective filters have the same flow face velocity and the same pressure drop as the real candle filters. Under these conditions, the effective permeability of the upper filters is estimated as $9 \times 10^{-13} \mathrm{~m}^{2}$, and that for the lower filter is taken as $2 \times 10^{-11} \mathrm{~m}^{2}$.

\section{SIMULATION PROCEDURE}

In this sections the grid schematics and the simulation procedure is described.

\section{Computational Grid}

An unstructured grid of 312,797 cells generated by GAMBIT as shown in Figure $3 a$ is used in the simulations. Figure $3 \mathrm{~b}$ shows the inner structure of the vessel. The inlet region, the shroud, the tube sheets, the effective upper six and one lower cylindrical filters and the outlet tube can be seen in this figure. In the simulation, z-axis is in the vertical direction and the $\mathrm{x}$-axis is along the inlet flow direction. As noted before, the Reynolds stress transport turbulence model was used in these computations.

\section{Gas Flow Simulation}

The Reynolds stress transport model of FLUENT-5.0 is adopted for evaluating the turbulent 
gas flow condition in the filter vessel. Earlier Ahmadi and Smith (1997, 1998a) showed that the temperature and density of gas do not vary to an appreciable extent in the FETC hot-gas filtration vessel. Likewise for the filter vessel at Wilsonville, it is expected that the variations of gas density and temperature were small. Therefore, the incompressible fluid option with a constant density and temperature is used in the simulation.

\section{Particle Trajectory Analysis}

A particle suspended in the gas is transported under the action of the drag, Brownian, gravitational, and lift forces. While the drag is generally the dominating force, in regions with a strong shear field, the lift force becomes important. The Brownian force becomes significant only for submicron particles. FLUENT version 5.0 used in the present simulation provides a provision for including the drag, gravitational, lift, and the Brownian forces for particle tracking in turbulent flows. However, for the filtration of particles of the order of I micron or larger, the Brownian motion is negligible and therefore is not activated. The mean gas velocity was evaluated by using the Reynolds stress transport model. The instantaneous fluctuating velocity field was evaluated using the Gaussian filtered white noise model of the FLUENT code. Additional details of the particle equation of motion model and particle trajectory analysis may be found in the FLUENT User's Guide (1998). 


\section{SIMULATION RESULTS}

In this section, results concerning particle transport and deposition in the filter vessel are presented. The turbulent gas flow field is studied first. Particles with different sizes then are introduced at the inlet section of the filter vessel and their trajectories are analyzed.

\section{Gas Flow}

Figure 4 shows the mean velocity magnitude contours in the plane at $x=0$ (midsection of the vessel). It is observed that the velocity magnitude inside the shroud is generally high. The gas velocity is relatively low inside the vessel. In the upper two comer regions, where gas leaves the shroud, the gas velocity is somewhat higher compared with the region inside the vessel. The gas velocity increases when gas passes through the filters and enters the outlet tube.

The velocity vector plots in the plane at $\mathrm{x}=\mathrm{O}$ are shown in Figures $5 \mathrm{a}$ and $5 \mathrm{~b}$. Figure 5 shows that part of the inlet gas moves upward in the shroud and the other part moves downward. Therefore, gas enters the body of the vessel both from the top and bottom of the shroud. The flow velocity is downward and somewhat larger in the region between the upper filter and the shroud. Near the top of the vessel, the upward gas flow in the shroud turns sharply downward to enter the mean body of the vessel. Also the downward gas flow near the outlet of the shroud at the bottom turns upward to enter the main body of the vessel. The formation of recirculating flow regions at several locations in the vessel can be seen in Figure 5. The recirculating flow zone increases the particle residence time, as well as the local intensity of gas turbulence and thus, contributes to the particle deposition rate. The presence of the recirculating flows could lead to the gradual buildup of ash in these regions.

The contour plots for variations of the static pressure in the plane at $\mathrm{x}=0$ are shown in Figure 6a. This figure shows that pressure remains almost constant inside the shroud and in the main body of the vessel. The gas pressure inside the filters is also roughly constant with a slight decrease toward the outlet. The main pressure drop is about $14 \mathrm{kPa}$ which occurs across the filter wall. Figure $6 \mathrm{~b}$ shows the contour plots for the static pressure at a section across the upper six filters. 
The sharp pressure drop across the filter wall is clearly seen from this figure.

Figure 7 shows the variations of the turbulence intensity in the filter vessel. The turbulent intensity is generally quit low in the vessel except for some regions inside the outlet tube. The contour plot of vorticity magnitude in the plane $x=0$ is shown in Figure 8 . It is observed that in the shroud region the vorticity is generally high. The inlet region and the regions near the upper and lower filter also have high vorticity.

\section{$\underline{\text { Particle Trajectory Analysis }}$}

Particle transport and deposition in the filter system is studied using the FLUENT code. Particle diameters of 1, 10, 60 and I $00 \mathrm{um}$ with a constant density of $2700 \mathrm{~kg} / \mathrm{M} 3$ are used in the computer simulations. Line and the uniform sources of particles at the inlet is used to analyze particle trajectories and their deposition rate.

\section{$\underline{\text { Line Source }}$}

In this section, simulation results for particles that are initially released from a line source at the middle of the inlet are presented. This line source is along the z-direction and each line source has 8 injectors equally spaced at a distance of $4.3 \mathrm{~cm}$. The particles are assumed to enter with the same velocity as the hot gas. The rebound condition for the walls and the stick condition for the filters are used in the simulations. A time duration of 50,000 time steps was also used in the particle trajectory analysis. The cases with or without gravity, turbulence fluctuation velocity, and lift forces are used to evaluate the effect of these different factors.

Samples $1 \mu \mathrm{m}$ particle trajectories released from the line source for different cases are shown in Figure 8. In this and subsequent figures, "a" denotes the case that includes the effects of turbulence dispersion, and the gravitational and lift forces. Similarly, "b" is for the case when turbulence dispersion effect is ignored, but the gravitational and lift forces are included. In these figures, "c" denotes the case that ignores turbulence dispersion and gravitational effects, but includes the lift 
force, and "d" identifies the case without gravitational, lift, and turbulence dispersion effects. Figure 9a shows that $1 \mu \mathrm{m}$ particles are transported by the highly swirling flow from the inlet both upward and downward through the shroud then enter the main body of the vessel. Four particles move upward and deposit on the upper filters and other particles travel downward and deposit on the lower filter. The average flight time for particles that deposit on the upper filter is $21.91 \mathrm{sec}$, while for particles that deposit on the lower filter, the average flight time is $97.77 \mathrm{sec}$. This is because particle spends much time in the recirculating region in the bottom of the vessel and also due to the turbulent dispersion effect. It is observed from Figure 9a that turbulence dispersion effect is important for small particles. Comparing the Figures 9c, 9d with Figure $8 \mathrm{~b}$ shows that the effect of gravity and lift force for small particles is small and only changes the particle trajectory slightly.

Figure 10 shows samples $11 \mu \mathrm{m}$ particle trajectories released from a line source. Here, four particles deposit on the upper filter with an average flight time of $23.2 \mathrm{sec}$, and the other four particles deposit on the lower filter with an average flight time of $60.35 \mathrm{sec}$. Figure 10 shows 11 $\mu m$ particles spend less time in the lower region of the vessel when compared with $1 \mu \mathrm{m}$ particles. The effect of turbulent effect is somewhat smaller for $10 \mu \mathrm{m}$ particles. Like $1 \mu \mathrm{m}$ particles, the effect of gravity and lift force is small for $10 \mu \mathrm{m}$ particles. The pattern of particle transport and deposition for particles with diameter smaller than $10 \mu \mathrm{m}$ are quite similar.

Samples $60 \mu \mathrm{m}$ particle trajectories are shown in Figure 11. Figure 11a shows that the turbulence dispersion effect is small for large particles, and the trajector ies of $60 \mu \mathrm{m}$ particles show little random fluctuations. It can be seen that four particles move roughly straight to the bottom of the vessel due to the gravity. Also the difference of trajectories for the cases with or without lift force is much more pronounced for such large particles. Therefore, the gravitational and lift forces are important for large particles with the diameter greater than $60 \mu \mathrm{m}$, and the turbulence dispersion effect is small due to the large particle inertia.

The results for $100 \mu \mathrm{m}$ particles in Figure 12 show that turbulence dispersion has very little effect on such large particle motion. The gravity, however, makes five particles to roughly move straight toward the vessel bottom. The lift force acting on these large particles becomes quite important and noticeable affects their trajectories. Figures 11 and 12 also show that the gravity significantly increases the direct deposition of large on the bottom of the vessel. 


\section{Uniform Source}

To study the particle deposition rate on the filter vessel, 400 particles of different sizes are uniformly released from the inlet with the same velocity as the flow. In this section, the stick boundary condition for filters and the rebound condition for walls are used. The uniform particle source is a reasonable assumption for the particle concentration condition in the inlet. For each size, ensembles of 400 mean particle trajectories are evaluated and their deposition patterns on the filters are analyzed.

The percentages of particle deposition on the upper and lower filters, as well as the direct deposition on the vessel bottom for different cases are shown in Tables 1-3. Table 1 is for the real case that includes turbulence dispersion and gravitational effects. Table 2 shows the simulation results for the case that the turbulence dispersion is ignored, but the gravity is included. Table 3 is for the case that both turbulence dispersion and gravity are absent.

Table 1 shows that the percentage of particles that directly deposit on the vessel bottom increases sharply with particle diameter. This is because gravity plays an important role on large particles motions, due to the increase of the sedimentation velocity. For the size range of 1 to $60 \mu \mathrm{m}$, the deposition rate on the lower filter is somewhat higher than that on the upper filter. The reason is that the shroud splits the gas flow and particles enter the vessel both form the top and from the bottom of the shroud. The net flow is downward inside the vessel. Thus, chance for deposition on the lower filter seems to be higher.

Table 2 shows that when the turbulence dispersion is neglected, the deposition rate on the upper filters increases, while that for the lower decreases. The direct deposition to the vessel bottom increases for particles smaller than $30 \mu \mathrm{m}$, but decreases for the $60 \mu \mathrm{m}$ particles. This indicates that turbulence dispersion effect is more important in the lower part of the vessel.

Table 3 shows that the gravity greatly affects large particle motion in the vessel. For the case when turbulence and gravitational effects are neglected, Table 3 shows that the deposition pattern for different size particles is almost the same. Furthermore, the particles are more likely to deposit on the lower filter when compared with the upper filter. In particular, the $60 \mu \mathrm{m}$ particles show much higher deposition rate on the lower filter. This is because in the absence of gravity, large size 
particles are re-entrained from the lower region of the vessel and are deposited on the lower filter.

Tables 4-6 show the average residence time for different size particles before their deposition on the filters under various conditions. Table 4 shows that the average residence time for particles that are depositing on the lower filter is more than three times that for the upper filters. This is because many particles that are deposited on the lower filters are captured by the recirculating flow regions and spend much time in the lower part of the vessel. The difference in the residence time becomes smaller for large particles. As is seen from Figures 11 and 12, when large particles move to the lower part of the vessel, the chance for their re-entrainment is very small.

Table 5 shows that the average residence time for small I and 10 am particles depositing on the lower filter decreases by a factor of two, when the effect of turbulence dispersion is ignored. The corresponding average residence time for large 30 and $60 \mu \mathrm{m}$ particles, however, remains almost the same. Table 6 shows that the gravity plays an important role on large particle transport and deposition processes. The average residence times are distorted when the gravitational effects are neglected. This is particularly the case for large particle.

\section{Conclusion}

In this work, particle transport and deposition in the hot-gas filter vessel at Wilsonville, AL is studied. The FLUENT code is used to simulate the mean turbulent flow field and the corresponding particle trajectories. Based on the presented results, the following conclusions may be drawn:

! The gas mean velocity magnitude inside the shroud is generally high, while the mean velocity is relatively low inside the vessel. The clean gas velocity in the outlet tube.

! The pressure inside the filter vessel is roughly uniform. The mail pressure drop occurs across the candle filter wall. The gas pressure inside the filter outlet pipe is also roughly constant with a slight decrease toward the outlet.

! The turbulent intensity is generally quit low in the vessel except for some regions near the inlet 
in the shroud and inside the outlet tube.

! In the shroud region the vorticity is generally high. The inlet region and the regions near the top and bottom of the filter vessel also have high vorticity.

! Particles are transported by the highly swirling flow from the inlet both upward and downward through the shroud and enter the main body of the vessel both from the top and bottom of the shroud.

! Turbulence dispersion and recirculating flow regions increases the particle residence time significantly.

! Turbulence dispersion effect is important for small particles ( $\leq \leq 10, \mathrm{um})$, while does not a significant effect on large particle transport and deposition

! The gravitational and lift forces are important for large particles with the diameter greater than $60 \mu \mathrm{m}$. The effect of gravity and lift force, however, is small for small particles.

! Large particles have higher direct deposit rate on the bottom of the vessel due to the action of gravitational sedimentation.

! The deposition rate on the lower filter is higher than that on the upper filter.

! The average residence time for particle deposition on the lower filter is much larger than that for the upper filter.

! Particles will impact the outer wall or the shroud due to the narrow highly swirling flow inside the shroud.

\section{ACKNOWLEGEMENT}

This support of the U.S. Department of Energy under grant DE-FC26-98FT4047 is gratefully acknowledged. The authors would like to thank Richard Dennis of Federal Energy Technology Center for many helpful comments. Thanks is also given to FLUENT Corporation for make code available to the authors. 


\section{REFERENCE}

Ahmadi, G., and Smith, D. H. (I 997). "Computational modeling of particle transport and deposition in hot-gas cleanup filter vessels," in Proceedings of the second international symposium on scale modeling, (ISSM-II), Lexington, KY, June 23-27, pp. 337-350.

Ahmadi, G., and Smith, D. H. (1998a). "Particle transport and deposition in a hot-gas cleanup pilot plant," Aerosol Sci. Technol. 29, 183-205.

Ahmadi, G., and Smith, D. H. (I 998b). "Gas flow and particle deposition in the hotgas filter vessel at the Tidd 70 MWE PFBC demonstration power plant," Aerosol Sci. Technol. 29, 206-223

Chiang, T. K. (1996). Private Communication.

Cleaver, J. W. and Yates, B. (1975) "A sublayer model for deposition of the particles from turbulent flow," Chem. Eng. Sci. 30, 983-992

FLUENT User's Guid (version 5) (1998) Fluent Inc., Lebanon, NH

Friedlander, S. K., and Johnstone, H. H. (1957). "Deposition of suspended particles from turbulent gas streams," Ind. Eng. Chem. 49, 1151-1156

Hidy, G. M. (1984). "Aerosols, an Industrial and Environmental Science," Academic Press, New York.

Hinds, W. C. (1982). "Aerosol Technology, Properties, Behavior, and Measurement of Airborne Particles," John Wiely and Sons, New York.

Hurley, J. P., Strobel, T. M., and Docter, B. A. (1995). "Hot-gas filter ash characterization," in Proceedings of the Coal-Fired power Systems '95 Review Meeting (H. M. McDaniel, D. Mollot, and V. K. Venkatarainan, eds.) DOE/METC-95/1018, U.S. Department of Energy, Morgantown Energy Technology Center, Morgantown, )W, June 27-29, pp449-463.

Li, A., and Ahmadi, G. (1993). "Deposition of aerosol on surface in a turbulent channel flow," Int. J. Eng. 31, 435-451

Li, A., Ahmadi, G., Bayer, R. G., andgaynes, M. A. (1994). "Aerosol particle deposition in an obstructed turbulent duct flow," J. Aero. Sci. 25, 91-112

Li, A., Ahmadi, G., Gaynes, M. A., and Bayer, R. G. (1995). "Aerosol particle deposition in a recirculating region," J. Adhesion 51, 87-103

Lippert, T. E., Bruck, G. J., Smeltzer, E. E., Newby, R. A., and Bachovchin, D. M. (1993). "Westinghouse filter update," in Proceeding of Advanced Coal-Fired Power System '93-Advances in IGCC and PFBC Review Meeting (D. L. Bonk, ed.)

DOE/METC-93/6131, U.S. Department of Energy, Morgantown Energy Technology Center, Morgantown, WV, June 28-30, pp. 497-512

Lippert, T. E., Bruck, G. J., Sanjana, Z. N., and Newby, R. A. (1994). "Westinghouse advanced particle filter system," in Proceeding of Advanced Coal-Fired Power System '94-Advances in IGCC and PFBC Review Meeting (H. M. McDaniel. R. K. Staubly, and V. K. Venkataraman, eds.) Vol. 1, DOE/METC-94/1008, U.S. Department of Energy, Morgantown Energy Technology Center, Morgantown, W, June 21-23, pp. 152-165.

Lippert, T. E., Bruck, G. J., Sanjana, Z. N., and Newby, R. A. (1995). "Westinghouse advanced particle filter system," in Proceeding of Advanced Coal-Fired Power System '95 Review Meeting H. M. McDaniel, D. Mollot, and V. Venkataraman, eds.) DOE/METC-95/1008, U.S. Department of Energy, Morgantown Energy Technology Center, Morgantown, W, June 27-29, pp. 123-139.

Mudd, M. J., and Hoffman, J. D. (I 993). "Initial operation of the Tidd PFBC hot-gas clean up 
filter," in Proceedings of the Coal-Fired power Systems '93-Advances in IGCC and PFBC Review Meeting (D. L. Bonk, ed.) DOE/METC-93/6131, U.S. Department of Energy, Morgantown Energy Technology Center, Morgantown, W, June 28-30, pp483495.

Mudd, M. J., and Hoffman, J. D. (1994). "Tidd PFBC hot-gas filter operation experience: July 1993-April 1994," in Proceedings of the Coal-Fired power Systems '94Advances in IGCC and PFBC Review Meeting (H. M. McDaniel, R. K. Staubly, and V. K. Venkataraman, eds.) DOE/METC-94/1008, U.S. Department of Energy, Morgantown Energy Technology Center, Morgantown, W, June 21-23, pp519-534.

Papavergos, P. G., and Hedley, A. B. (1984). "Particle deposition behavior from turbulent flow," Chem. Eng. Des. 62, 275-295

Pontius, D. H. (1995). "Hot gas filtration technical issues," in Proceedings of the Coal-Fired power Systems '95 Review Meeting (H. M. McDaniel, D.Mollot, and V. K. Venkatarainan, eds.) DOE/METC-95/1018, U.S. Department of Energy, Morgantown Energy Technology Center, Morgantown, W, June 27-29, pp. 531-546.

Rockey, J. M., et al., (1995). "High temperature high pressure filtration and sorbent program," METC/Shell Cooperative Agreement, CRADA 93-01 1, Vol. I and Vol. II, Morgantown Energy Technology Center, Morgantown, WV.

Smith, D. H., Powell, V., Ahamdi, G., and Ibrahim, H. (1997a). "Analysis of operational filtration data-Part I: Ideal candle filter behavior, " Powder Technol. 94, 5-21 Smith, D. H., Haddad, G. J., and Grimm, U. (1997b). "Composition and Chemistry of particulates from a PFBC demonstration plant," Fuel. 76, 727-732

Smith, D. H., Powell, V., and Ahamdi, G. (1998a). "Analysis of operational filtration data-Part 11: Incomplete filter cleaning," Powder Technol. 97, 139-145

Smith, D. H., Powell, V., Ahamdi, G. and Ferer, M. (1998b). "Amalysis of operational filtration data-Part III: Re-entrainment and incomplete cleaning of dust cake," Aerosol Sci. Technol. 29, 224-235

Southern Research Institute (1993). "Assessment of ash characteristics from gas stream cleanup facilities," Topical Report, Contract No. DEAC21-89MC26239.

Thambimuthu, K. V. (1993). "Gas cleaning for advanced coal-based power generation," IEACR/53, IEA Coal Research, London

Wood, N. B. (I 98 la) "A simple method for the calculation of turbulent deposition to smooth and rough surfaces," J. Aerosol Sci. 12, 275-290

Wood, N. B. (1981b) "The mass transfer of particle and acid vapor to cooled surfaces," J. Institute of Energy, 76, 76-93. J. Aerosol Sci. 12, 275-290 
Table 1. Number and Percentage of Deposited Particles

(Turbulence dispersion and gravitational effects are included)

\begin{tabular}{|c|c|c|c|c|}
\hline Diameter & $\begin{array}{c}\text { Number of Deposited } \\
\text { Particles on the Filters }\end{array}$ & Upper Filter & Lower Filter & $\begin{array}{c}\text { Bottom or } \\
\text { Incomplete }\end{array}$ \\
\hline $1 \mu \mathrm{m}$ & 398 & 0.403 & 0.592 & 0.005 \\
\hline $10 \mu \mathrm{m}$ & 397 & 0.402 & 0.590 & 0.008 \\
\hline $30 \mu \mathrm{m}$ & 309 & 0.360 & 0.413 & 0.227 \\
\hline $60 \mu \mathrm{m}$ & 190 & 0.230 & 0.245 & 0.525 \\
\hline
\end{tabular}

Table 2. Number and Percentage of Deposited Particles

(Without turbulence dispersion and with gravitational effect)

\begin{tabular}{|c|c|c|c|c|}
\hline Diameter & $\begin{array}{c}\text { Number of Deposited } \\
\text { Particles on the Filters }\end{array}$ & Upper Filter & Lower Filter & $\begin{array}{c}\text { Bottom or } \\
\text { Incomplete }\end{array}$ \\
\hline $1 \mu \mathrm{m}$ & 382 & 0.415 & 0.540 & 0.045 \\
\hline $10 \mu \mathrm{m}$ & 375 & 0.435 & 0.502 & 0.063 \\
\hline $30 \mu \mathrm{m}$ & 266 & 0.297 & 0.368 & 0.335 \\
\hline $60 \mu \mathrm{m}$ & 229 & 0.333 & 0.240 & 0.427 \\
\hline
\end{tabular}

Table 3. Number and Percentage of Deposited Particles

(Without turbulence dispersion and gravitational effect)

\begin{tabular}{|c|c|c|c|c|}
\hline Diameter & $\begin{array}{c}\text { Number of Deposited } \\
\text { Particles on the Filters }\end{array}$ & Upper Filter & Lower Filter & $\begin{array}{c}\text { Bottom or } \\
\text { Incomplete }\end{array}$ \\
\hline $1 \mu \mathrm{m}$ & 383 & 0.427 & 0.530 & 0.043 \\
\hline $10 \mu \mathrm{m}$ & 384 & 0.458 & 0.502 & 0.040 \\
\hline $30 \mu \mathrm{m}$ & 387 & 0.455 & 0.513 & 0.032 \\
\hline $60 \mu \mathrm{m}$ & 397 & 0.390 & 0.602 & 0.008 \\
\hline
\end{tabular}


Table 4. Average Residence Time

(Turbulence dispersion and gravitational effects included)

\begin{tabular}{|c|c|c|}
\hline Diameter & Upper Filter $(\mathrm{sec})$ & Lower Filter $(\mathrm{sec})$ \\
\hline $1 \mu \mathrm{m}$ & 15.142 & 52.023 \\
\hline $10 \mu \mathrm{m}$ & 13.556 & 60.510 \\
\hline $30 \mu \mathrm{m}$ & 13.820 & 36.746 \\
\hline $60 \mu \mathrm{m}$ & 10.436 & 27.034 \\
\hline
\end{tabular}

Table 5. Average Residence Time

(Without turbulence dispersion and with gravitational effect)

\begin{tabular}{|c|c|c|}
\hline Diameter & Upper Filter $(\mathrm{sec})$ & Lower Filter $(\mathrm{sec})$ \\
\hline $1 \mu \mathrm{m}$ & 15.617 & 36.131 \\
\hline $10 \mu \mathrm{m}$ & 17.565 & 31.993 \\
\hline $30 \mu \mathrm{m}$ & 16.613 & 36.878 \\
\hline $60 \mu \mathrm{m}$ & 11.411 & 27.123 \\
\hline
\end{tabular}

Table 6. Average Residence Time

(Without turbulence dispersion and gravitational effect)

\begin{tabular}{|c|c|c|}
\hline Diameter & Upper Filter $(\mathrm{sec})$ & Lower Filter $(\mathrm{sec})$ \\
\hline $1 \mu \mathrm{m}$ & 10.436 & 27.034 \\
\hline $10 \mu \mathrm{m}$ & 16.337 & 34.329 \\
\hline $30 \mu \mathrm{m}$ & 20.579 & 34.285 \\
\hline $60 \mu \mathrm{m}$ & 26.703 & 37.239 \\
\hline
\end{tabular}



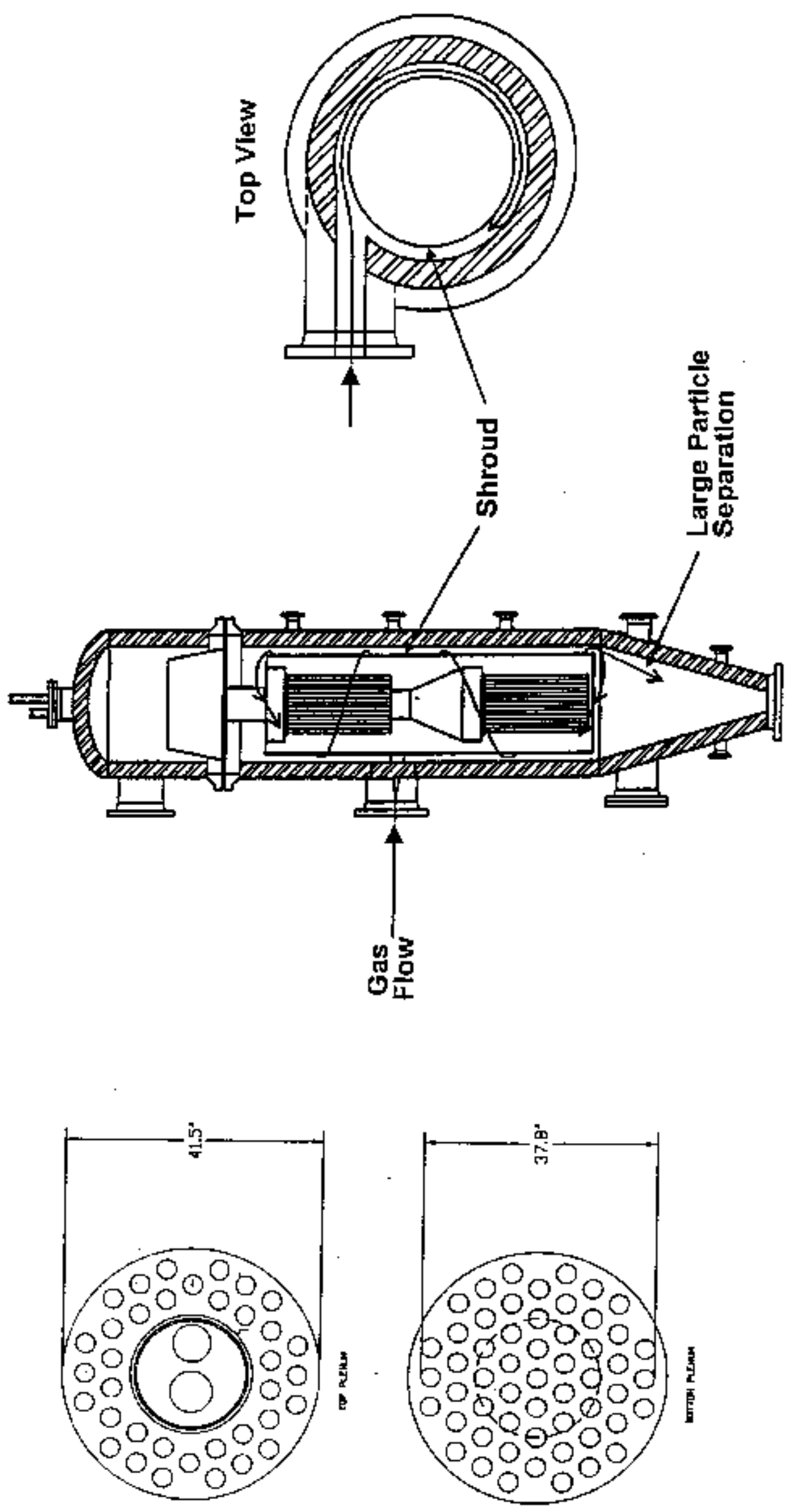


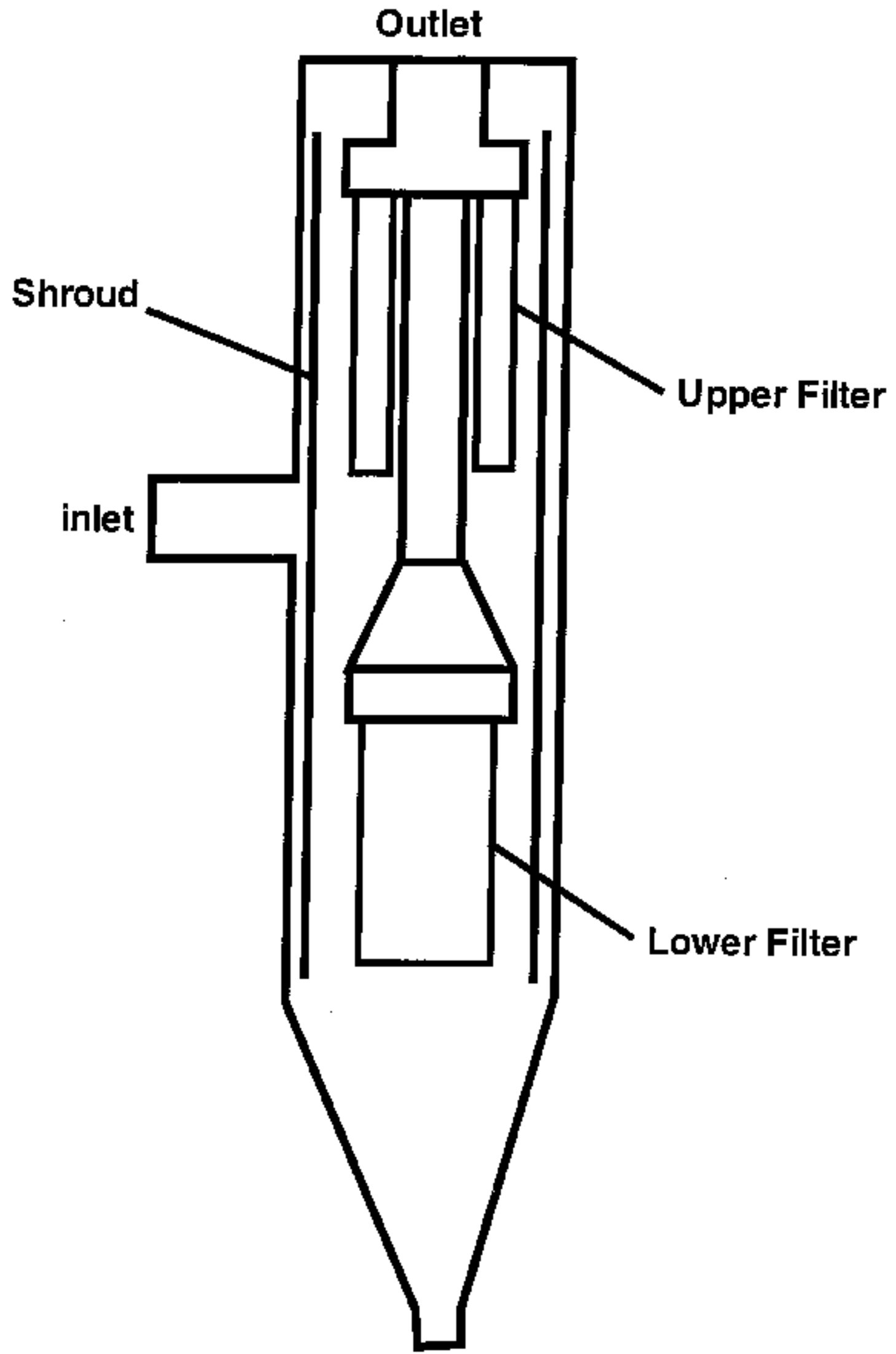



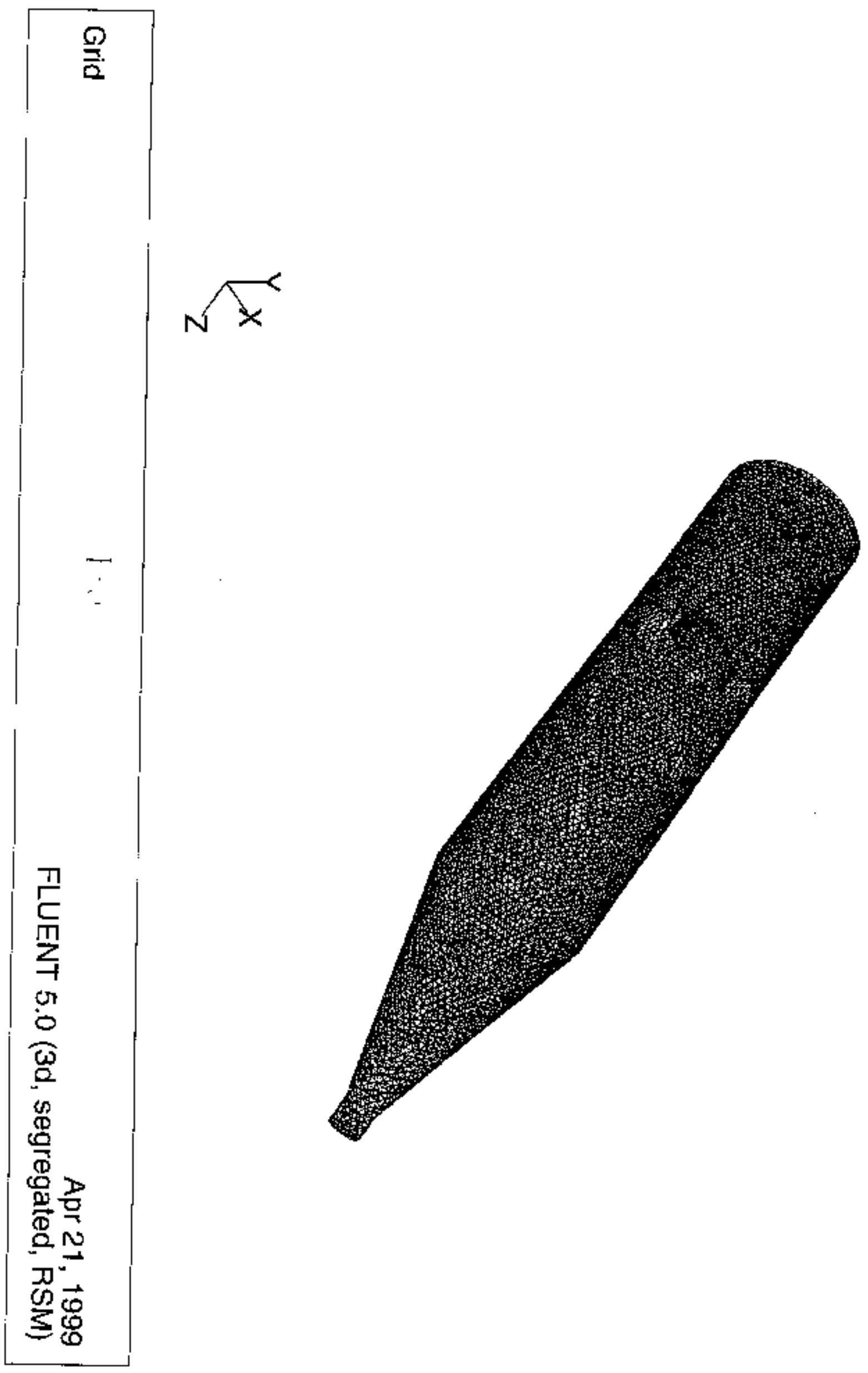


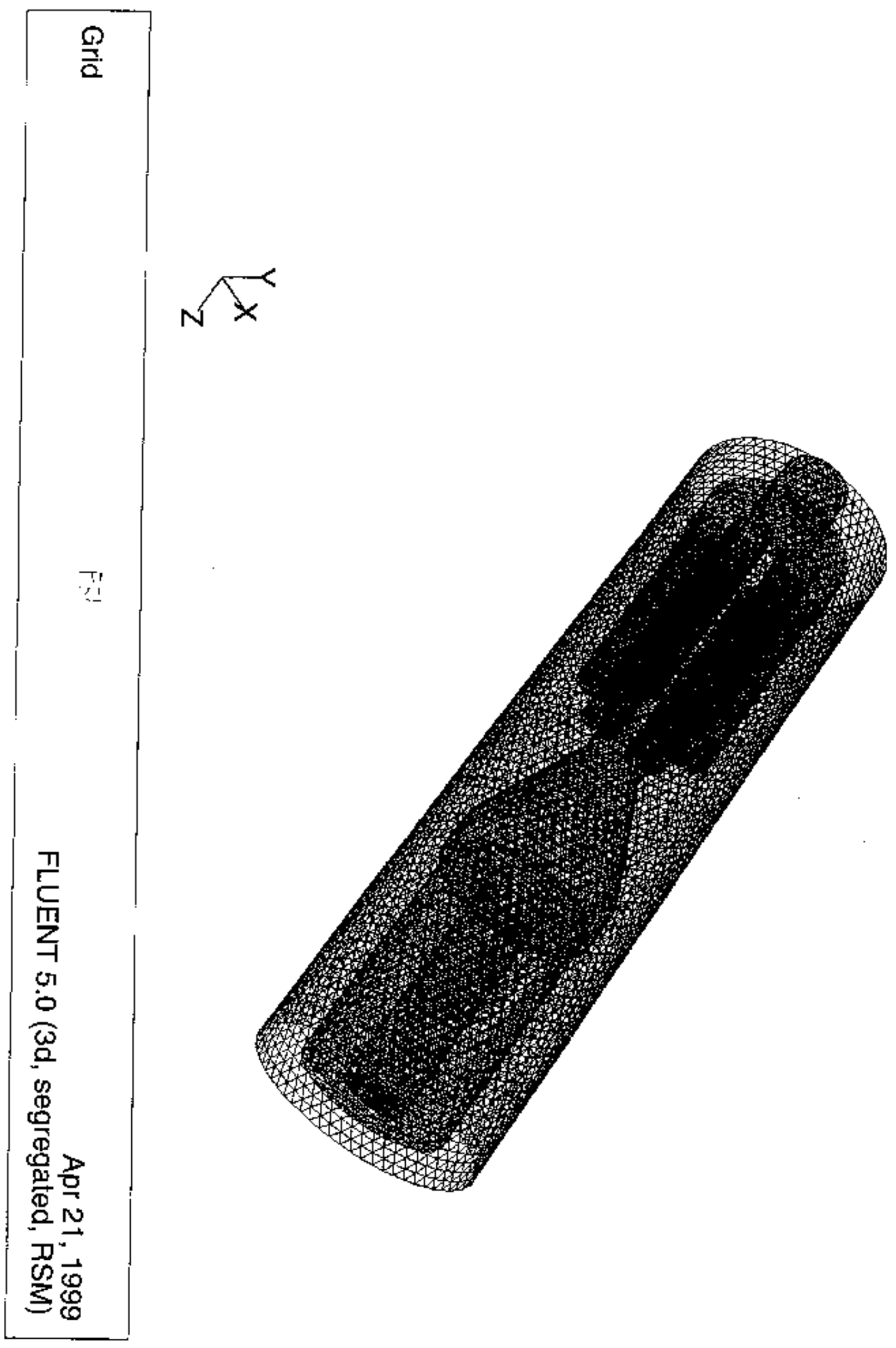




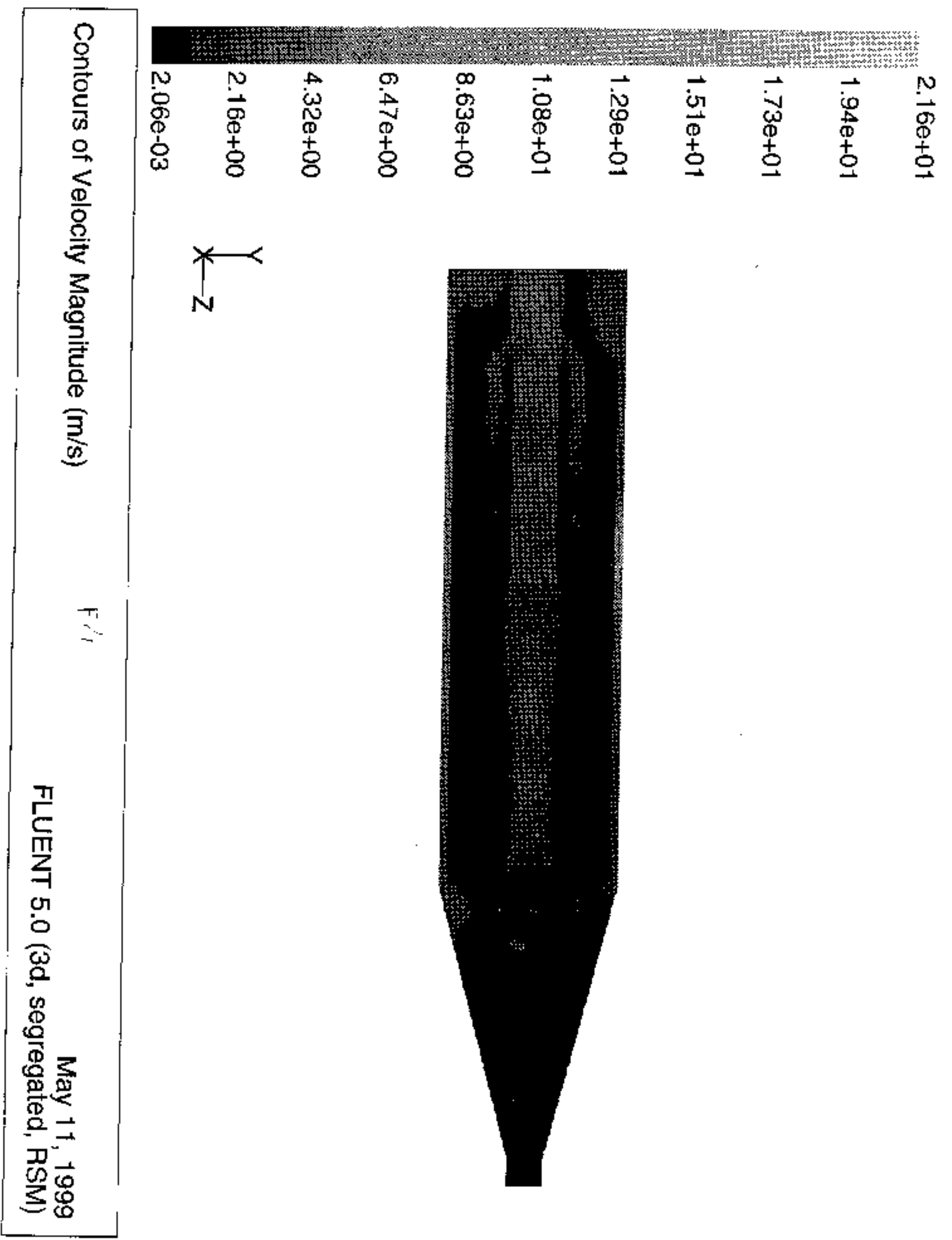




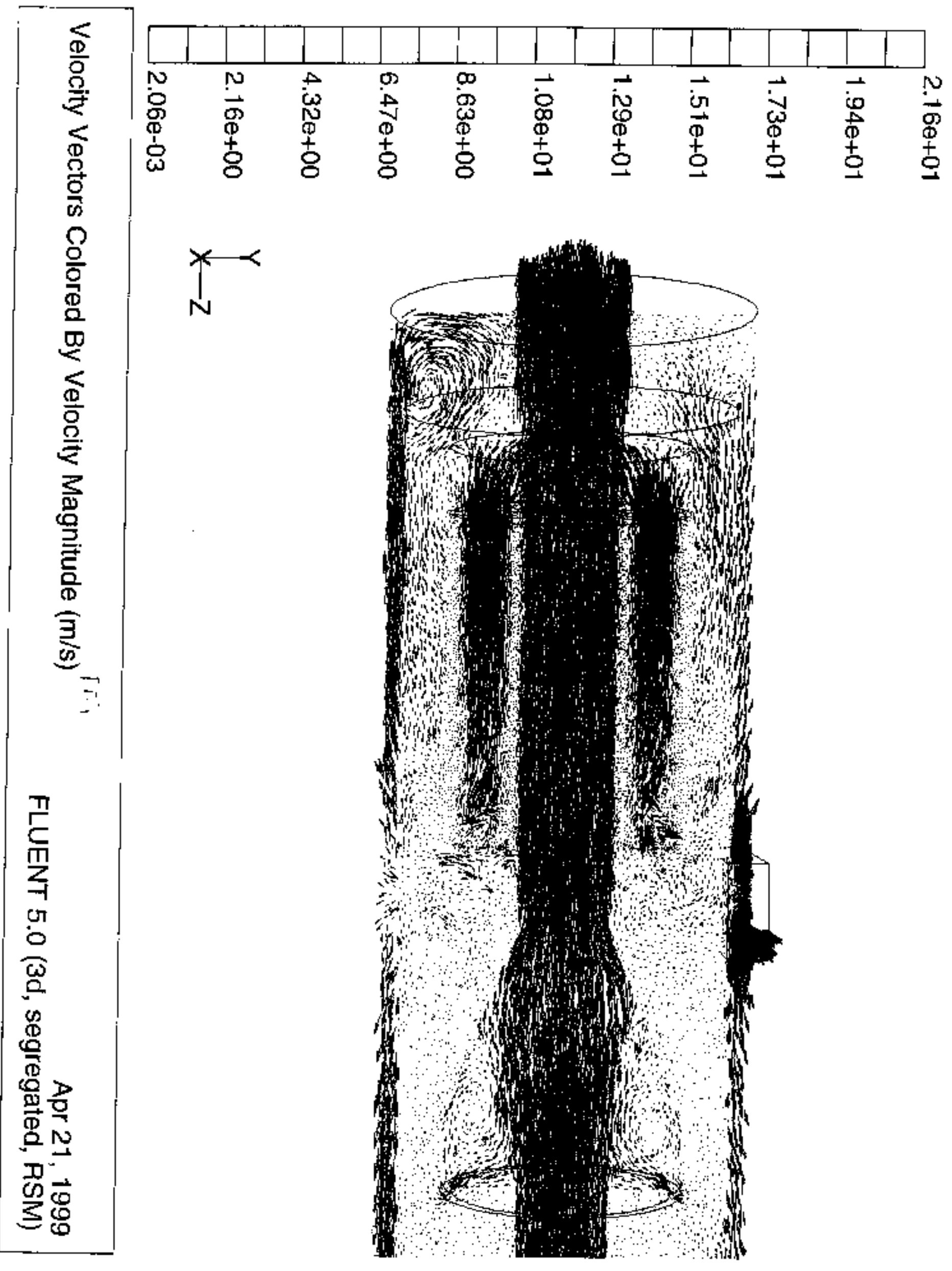




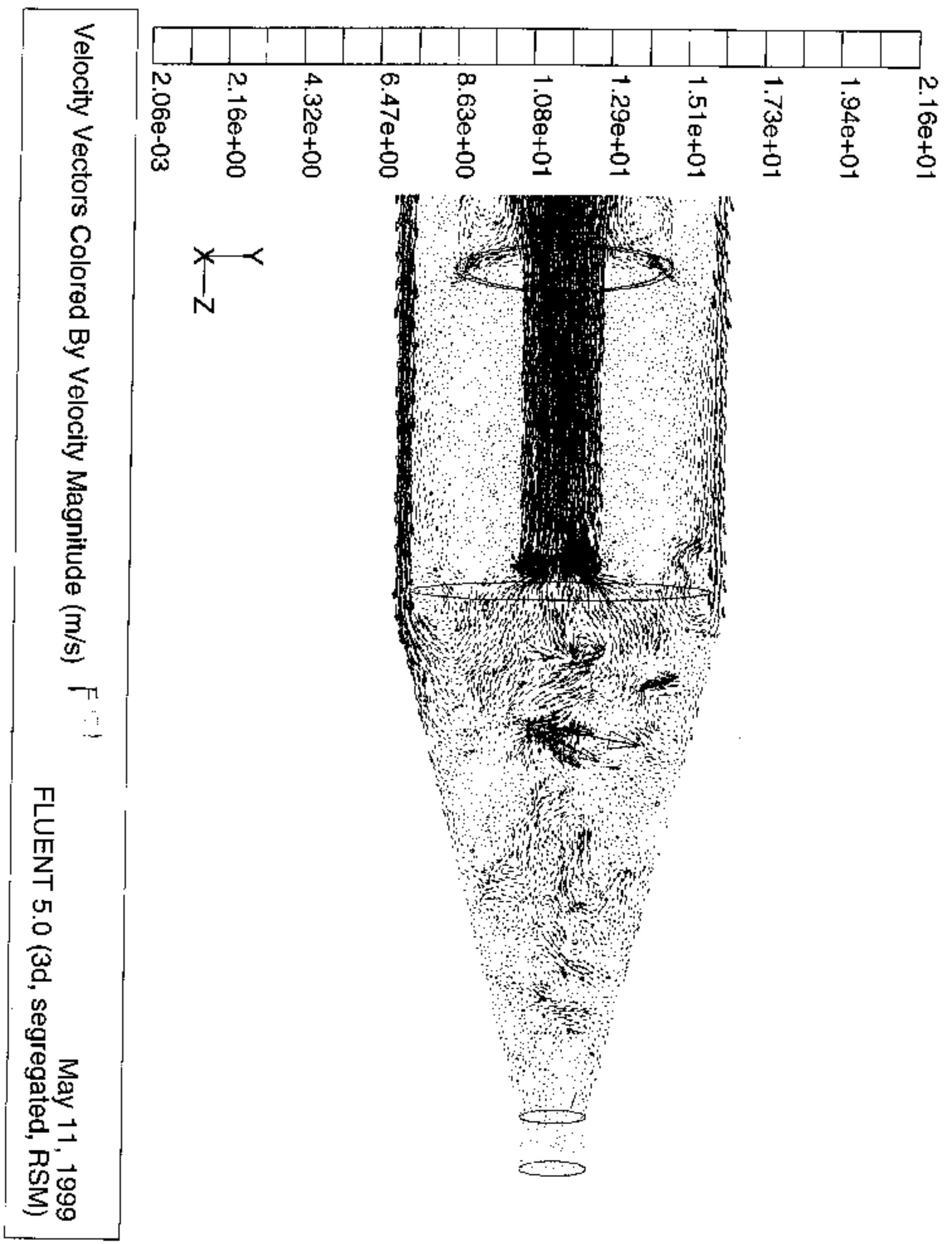




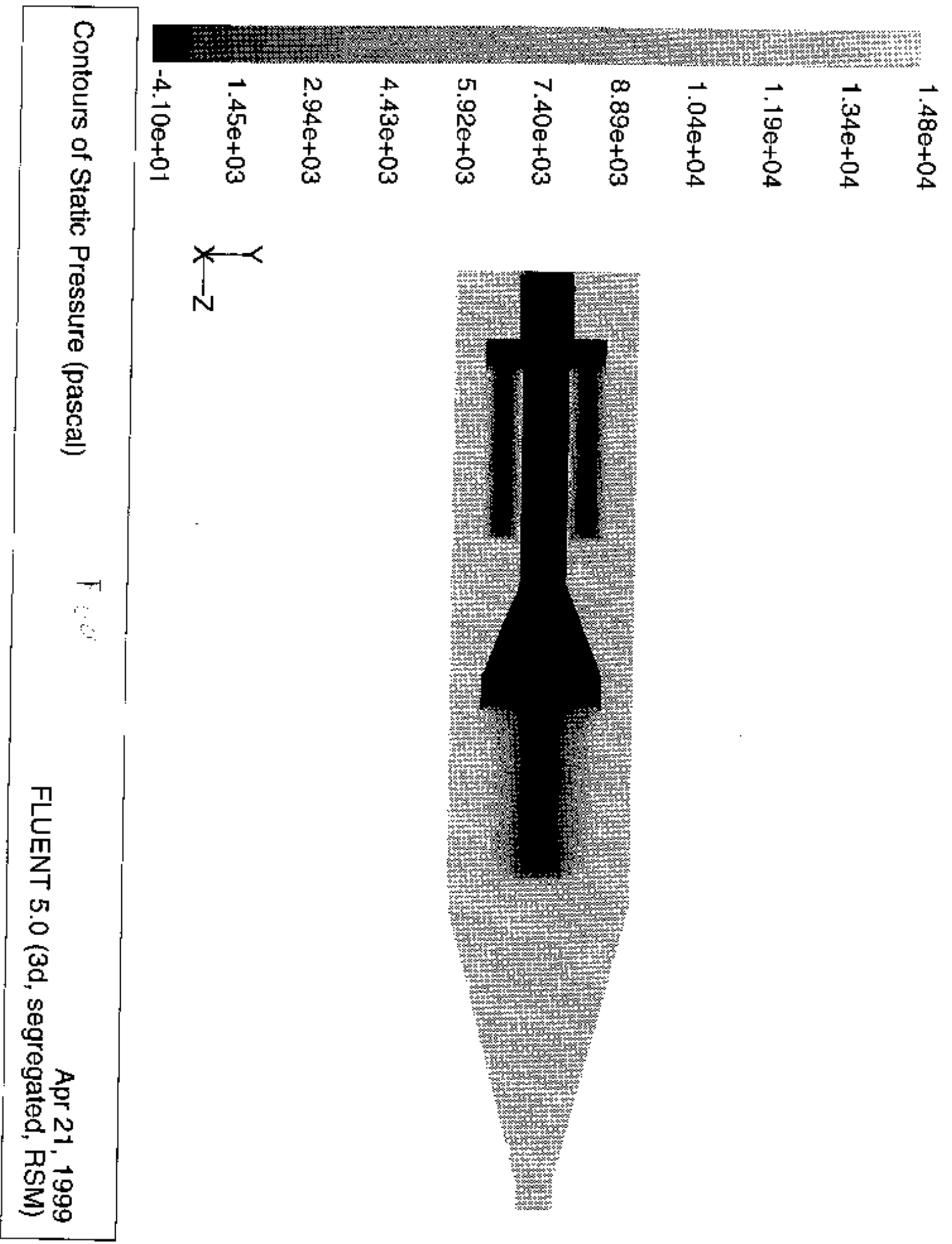




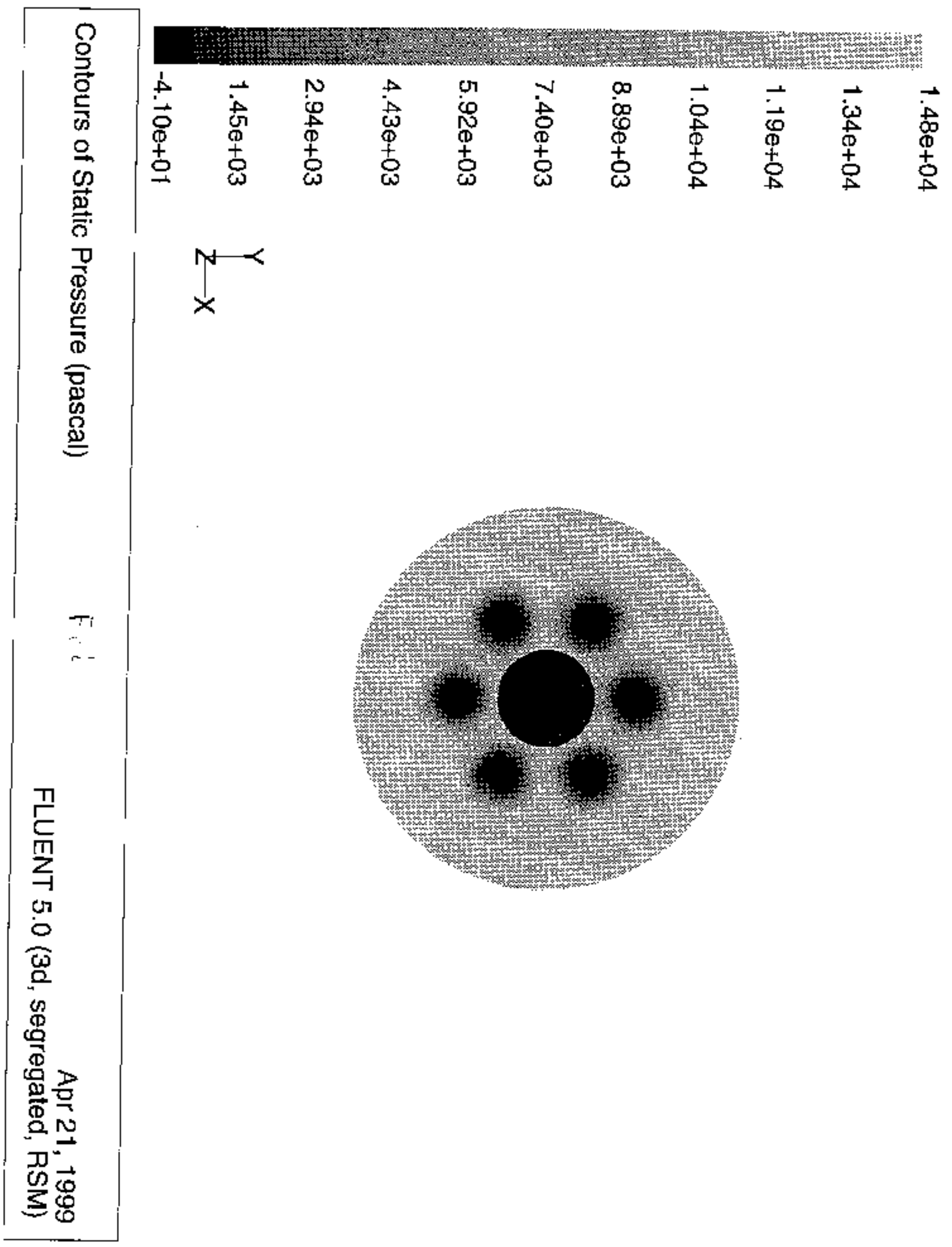




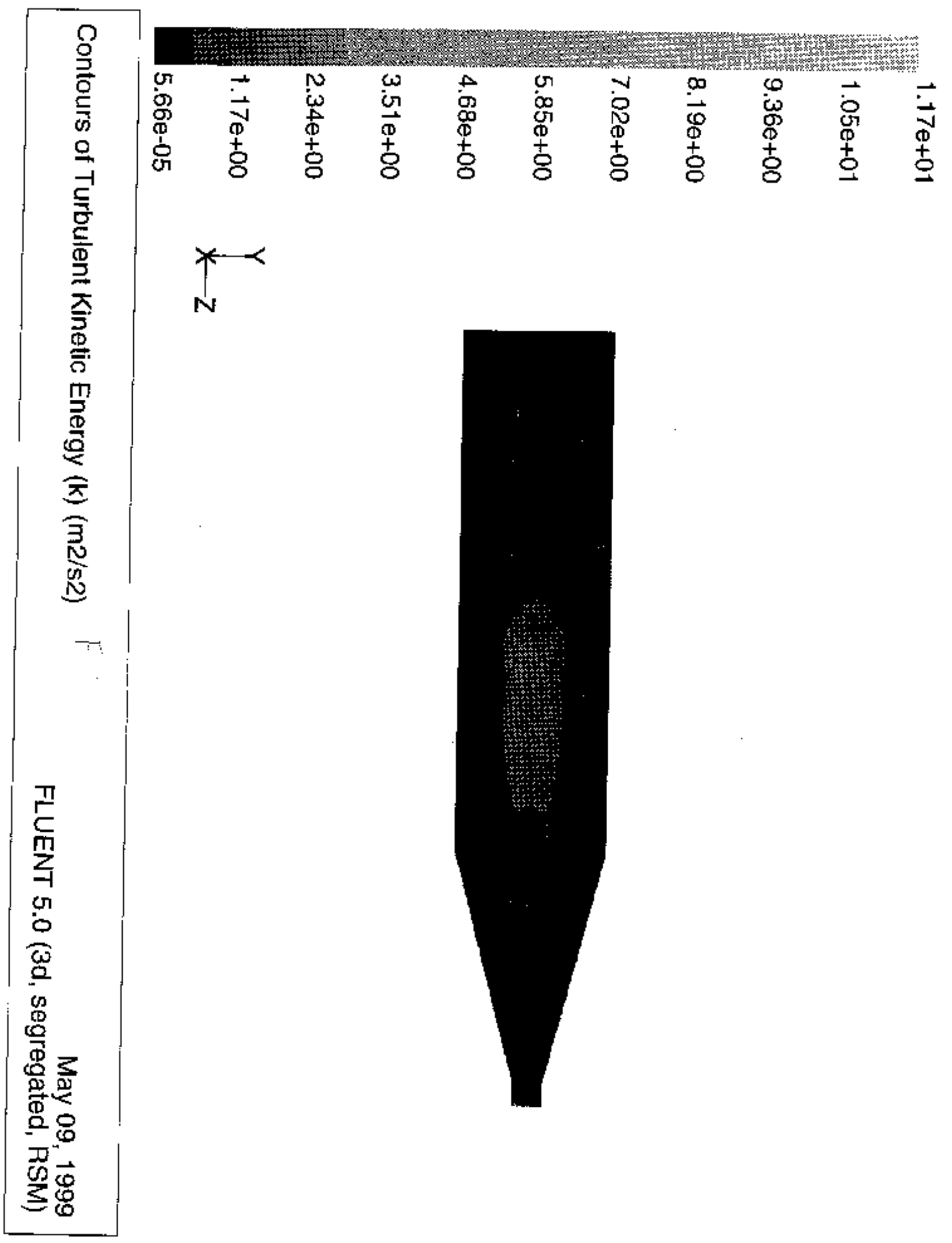




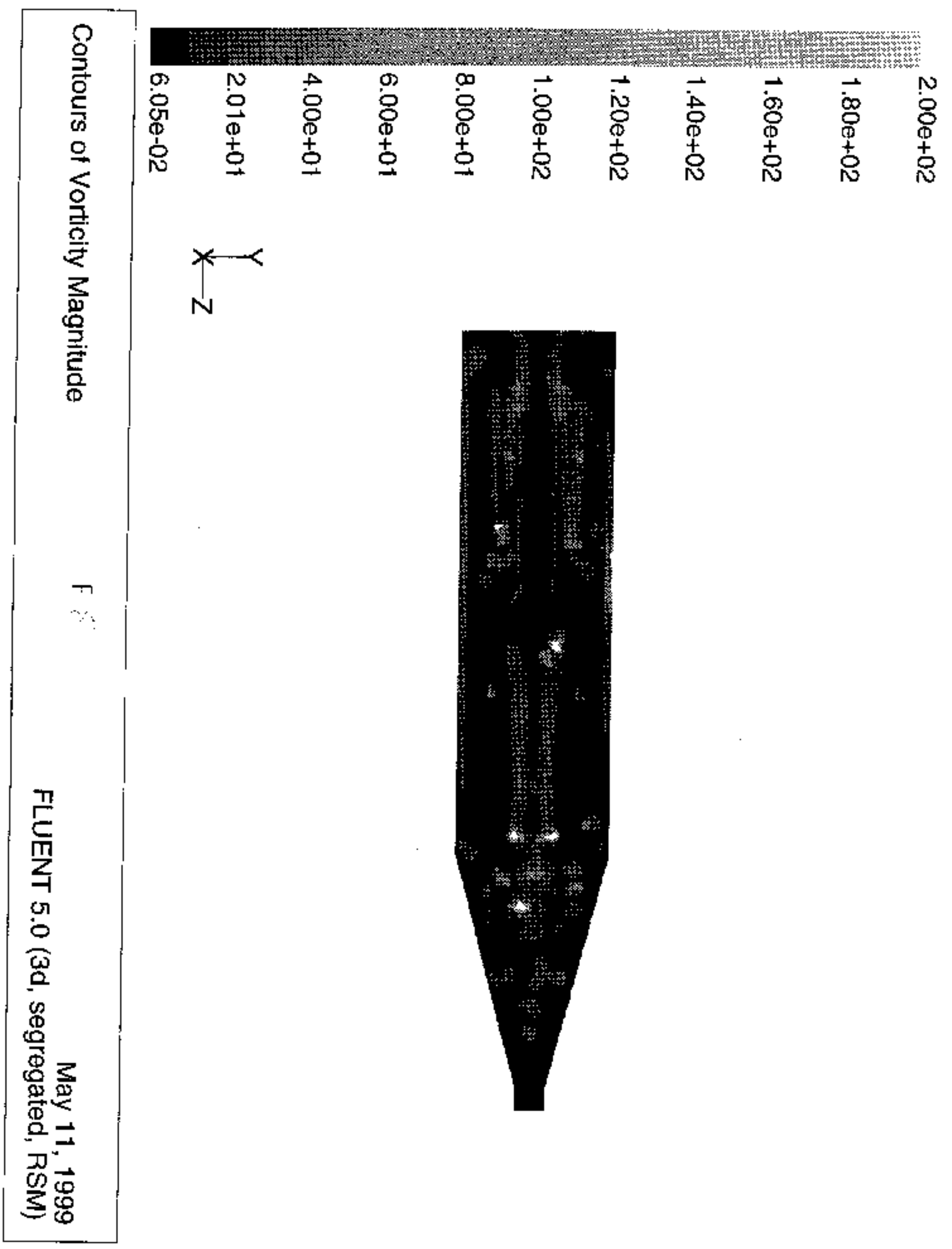




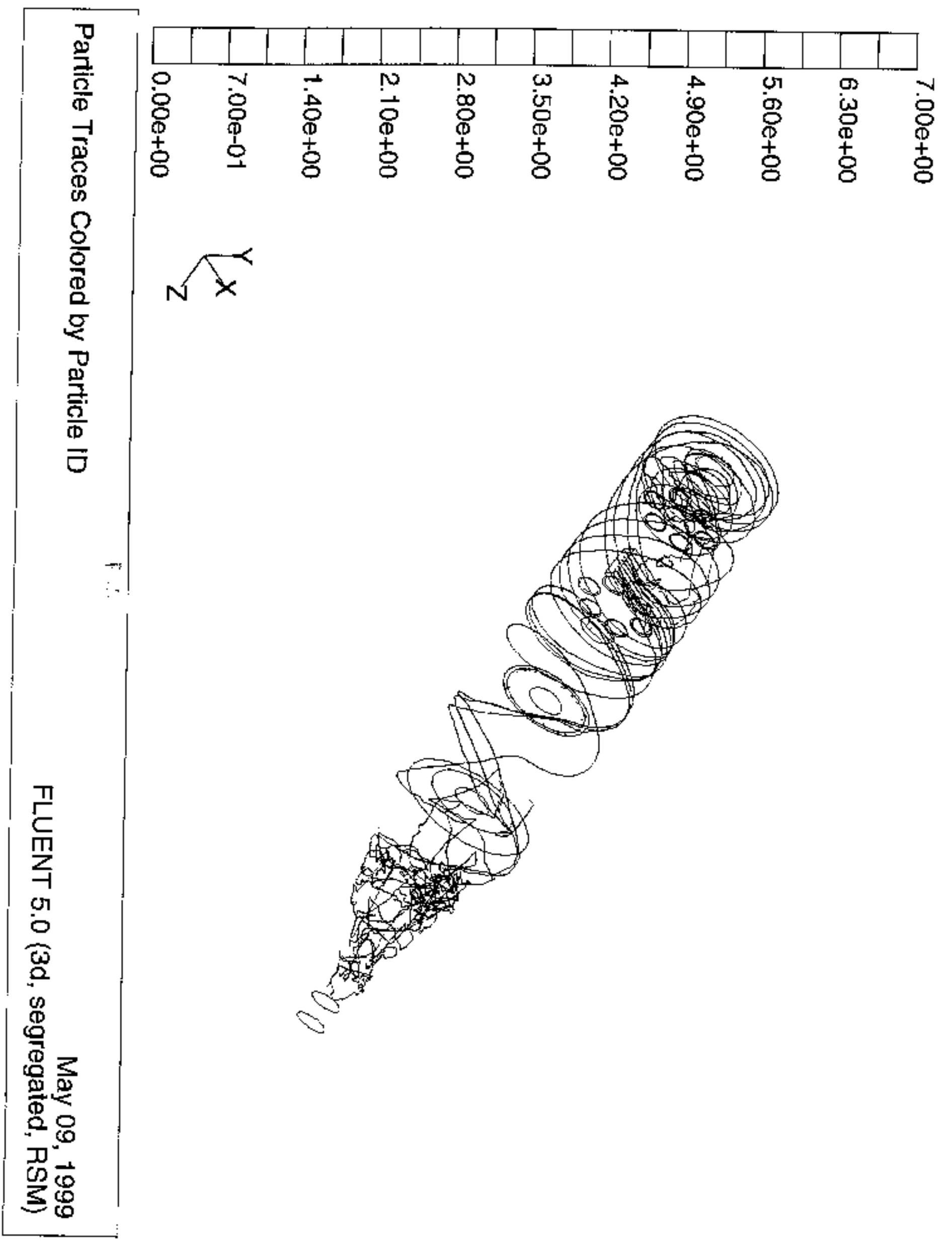




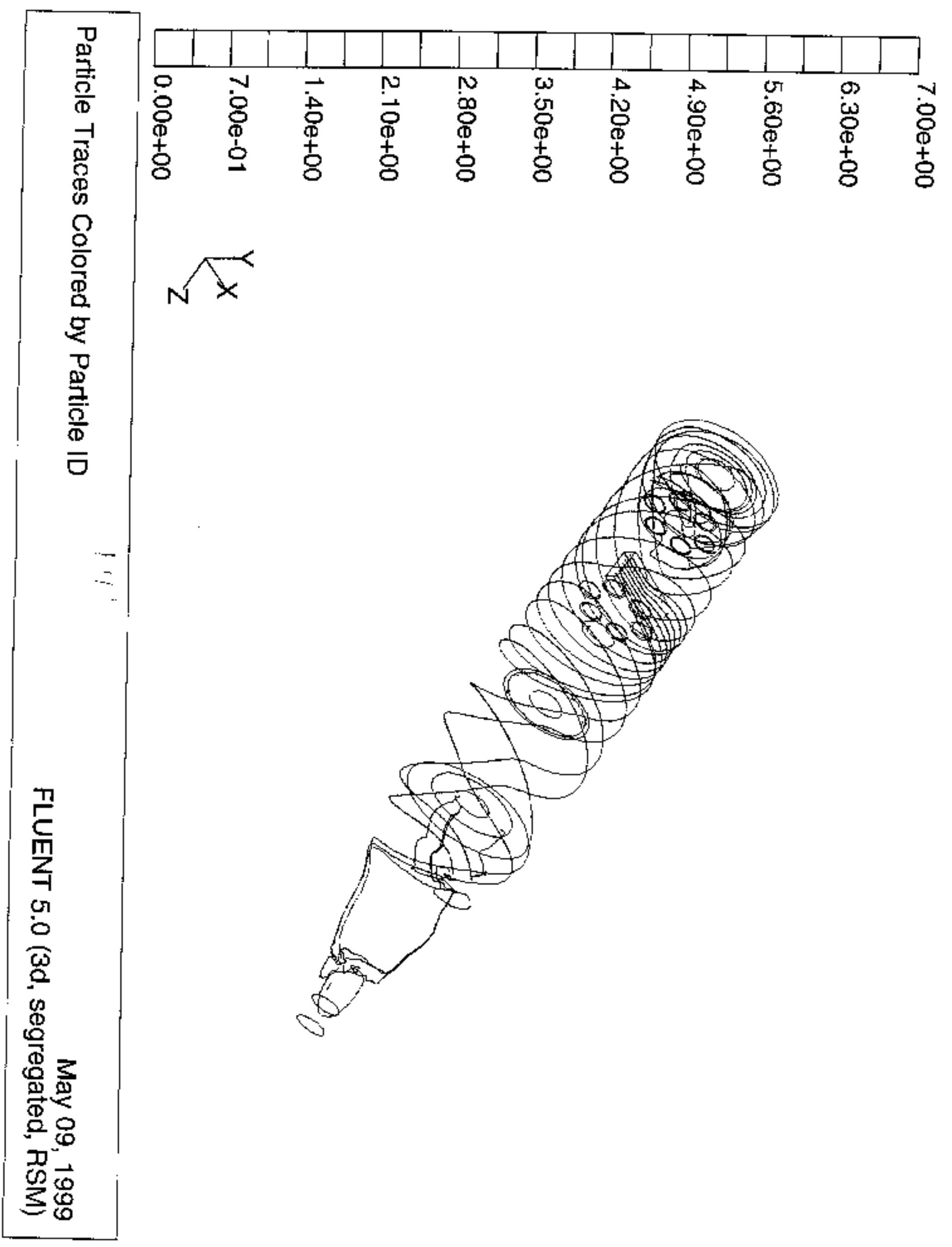




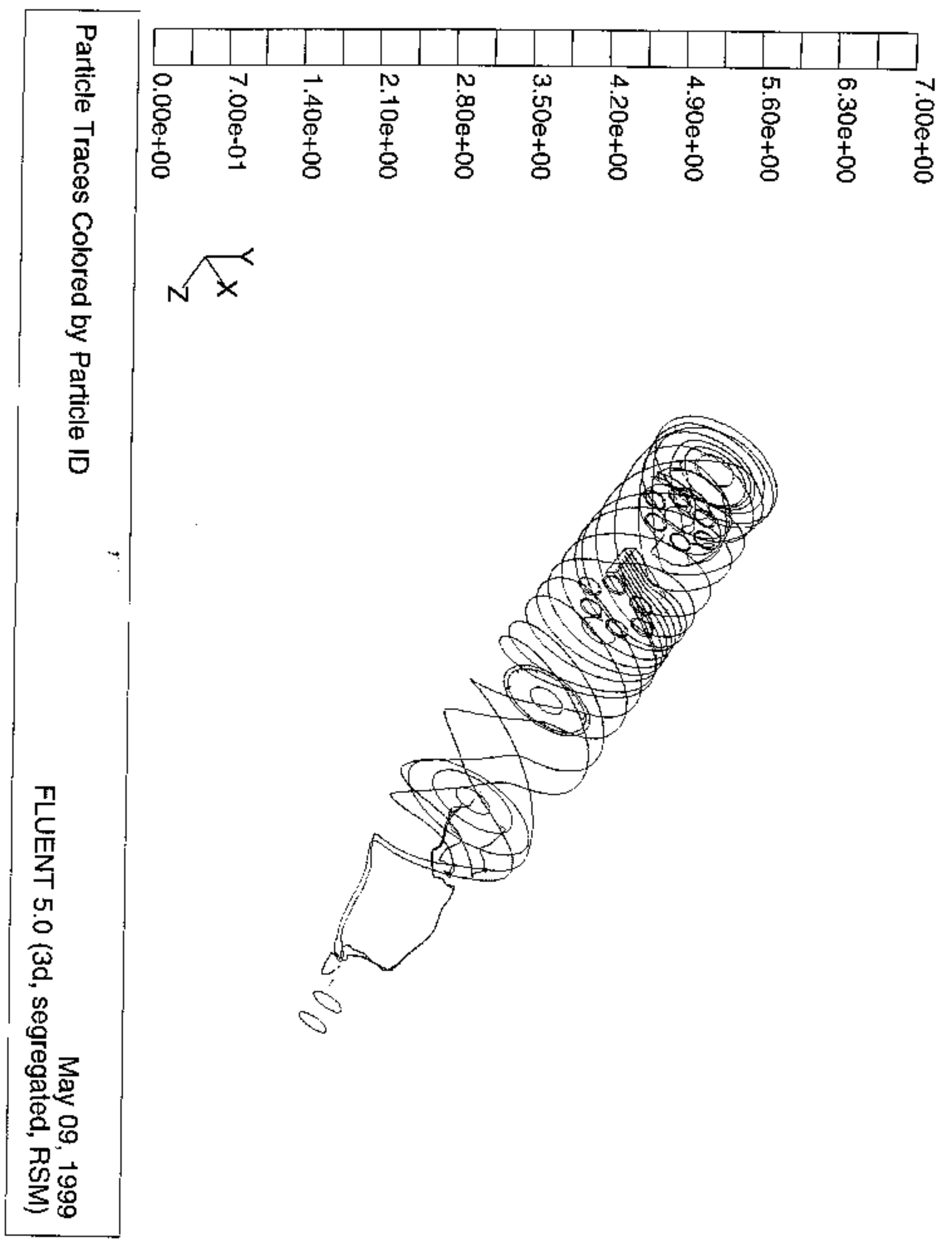




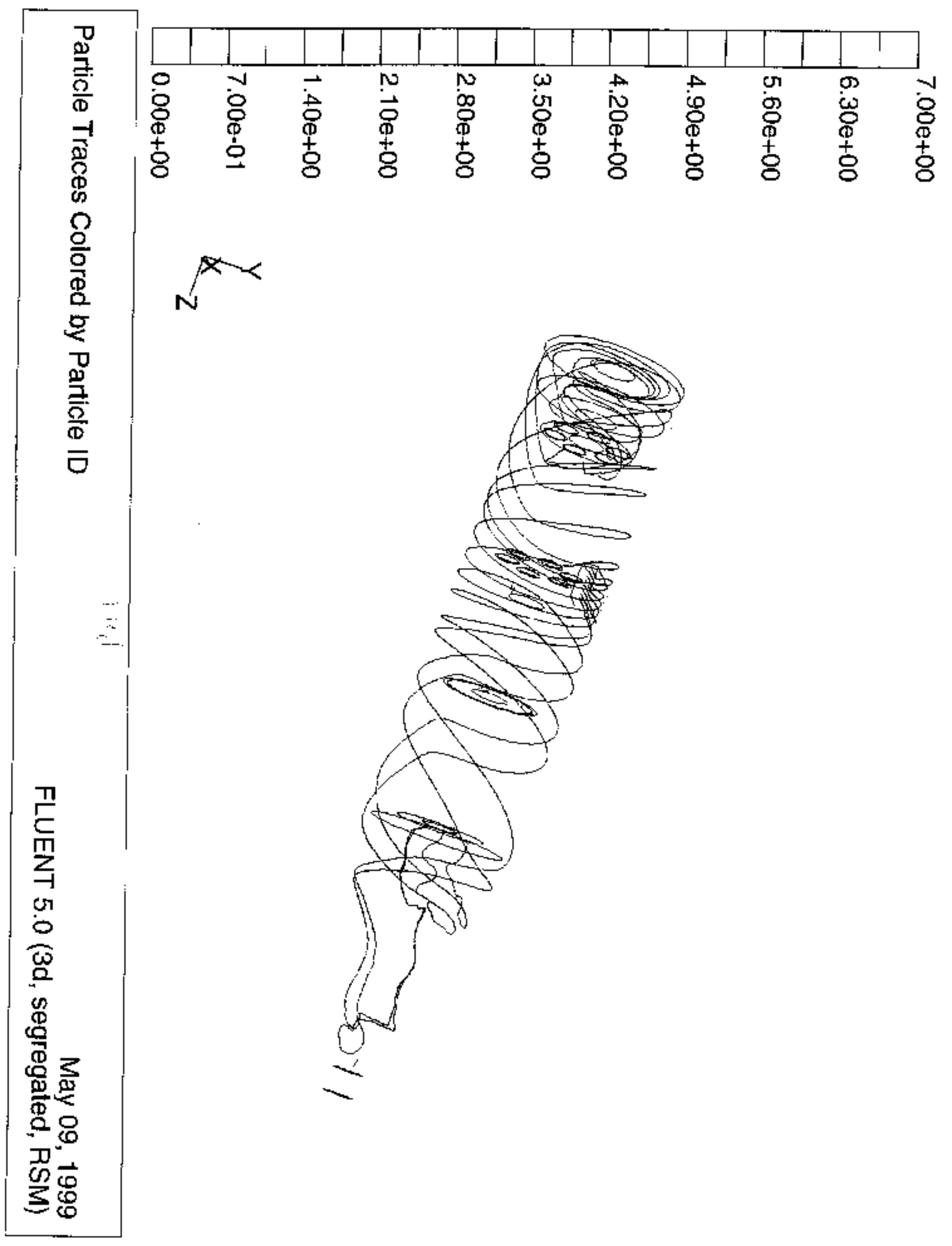




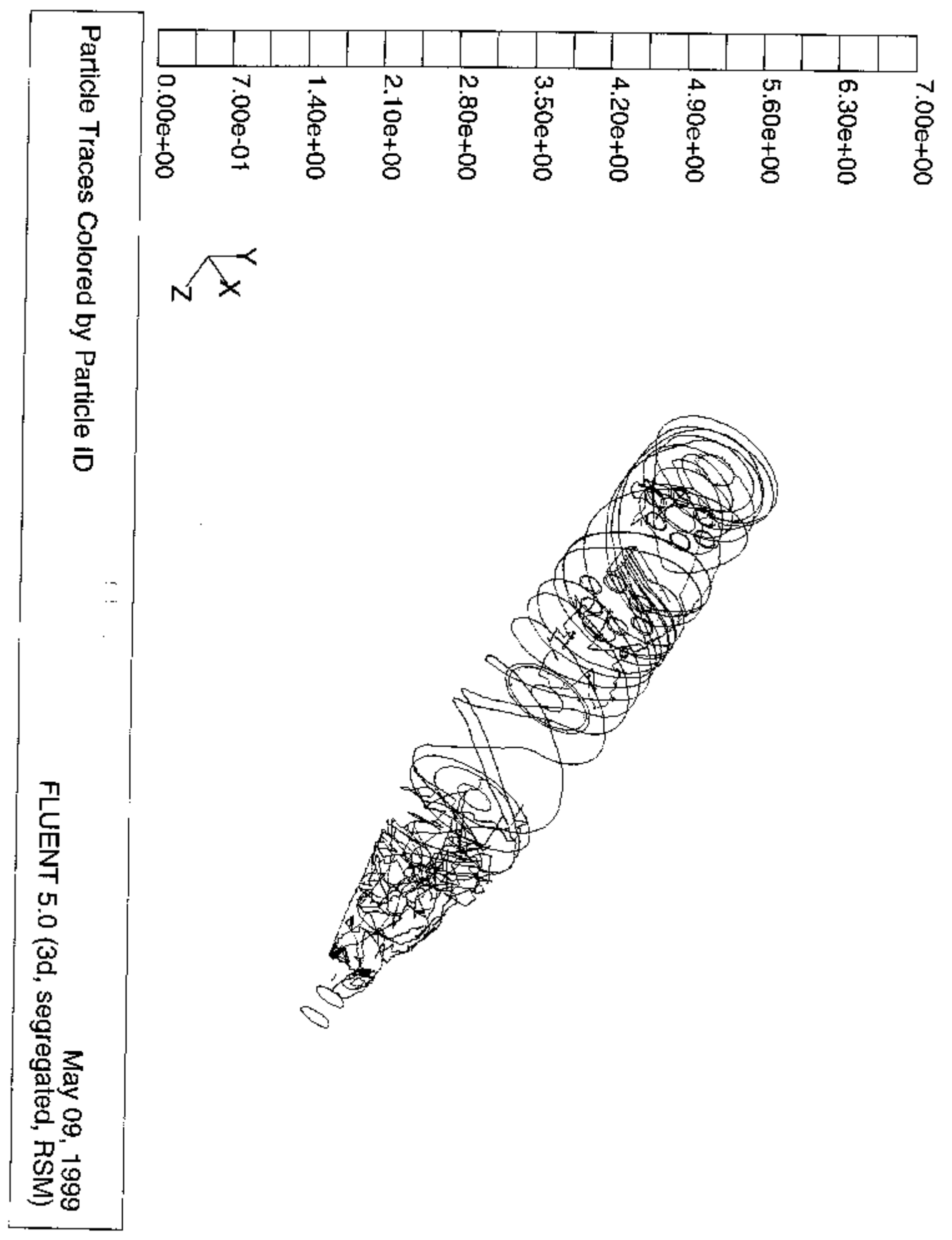




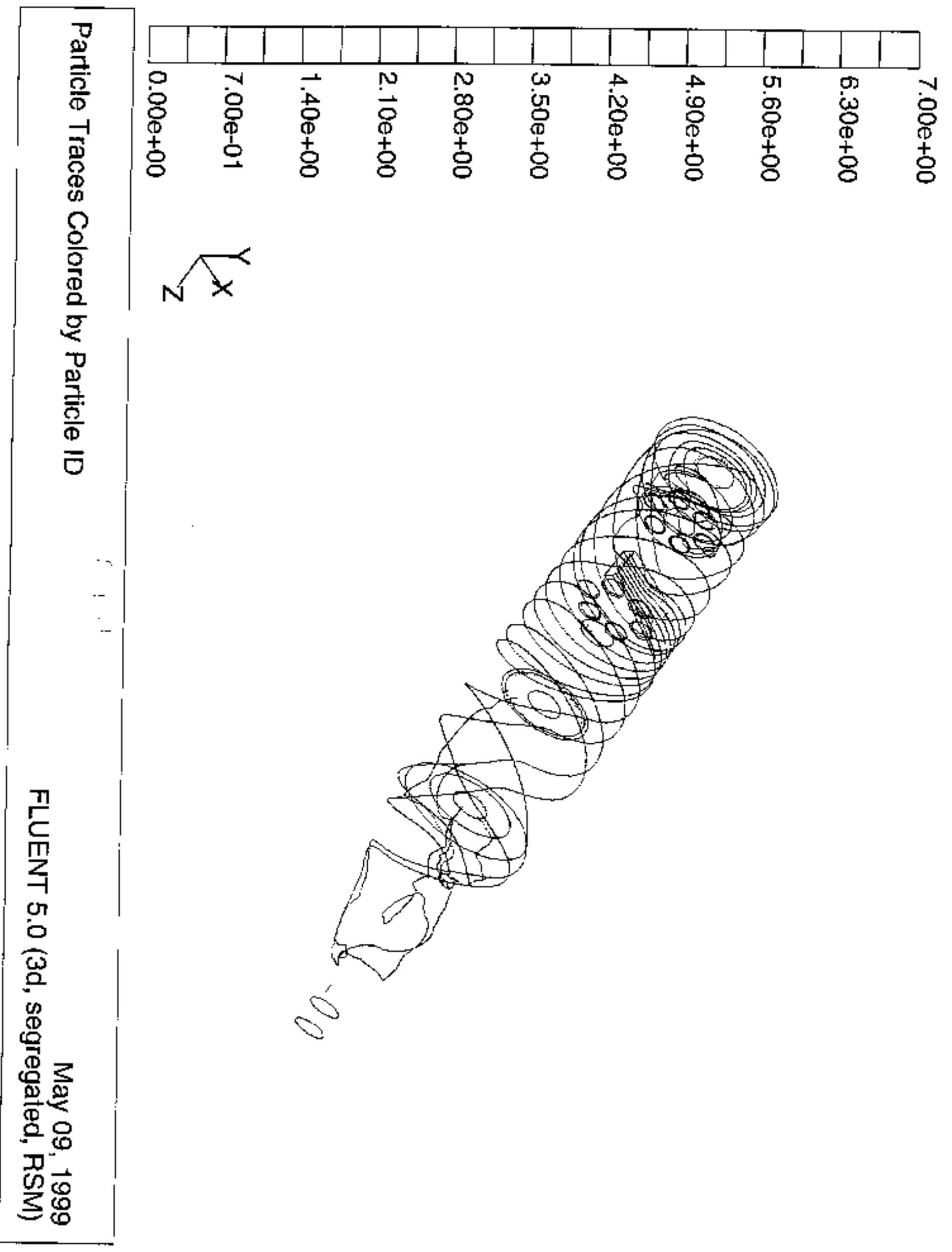




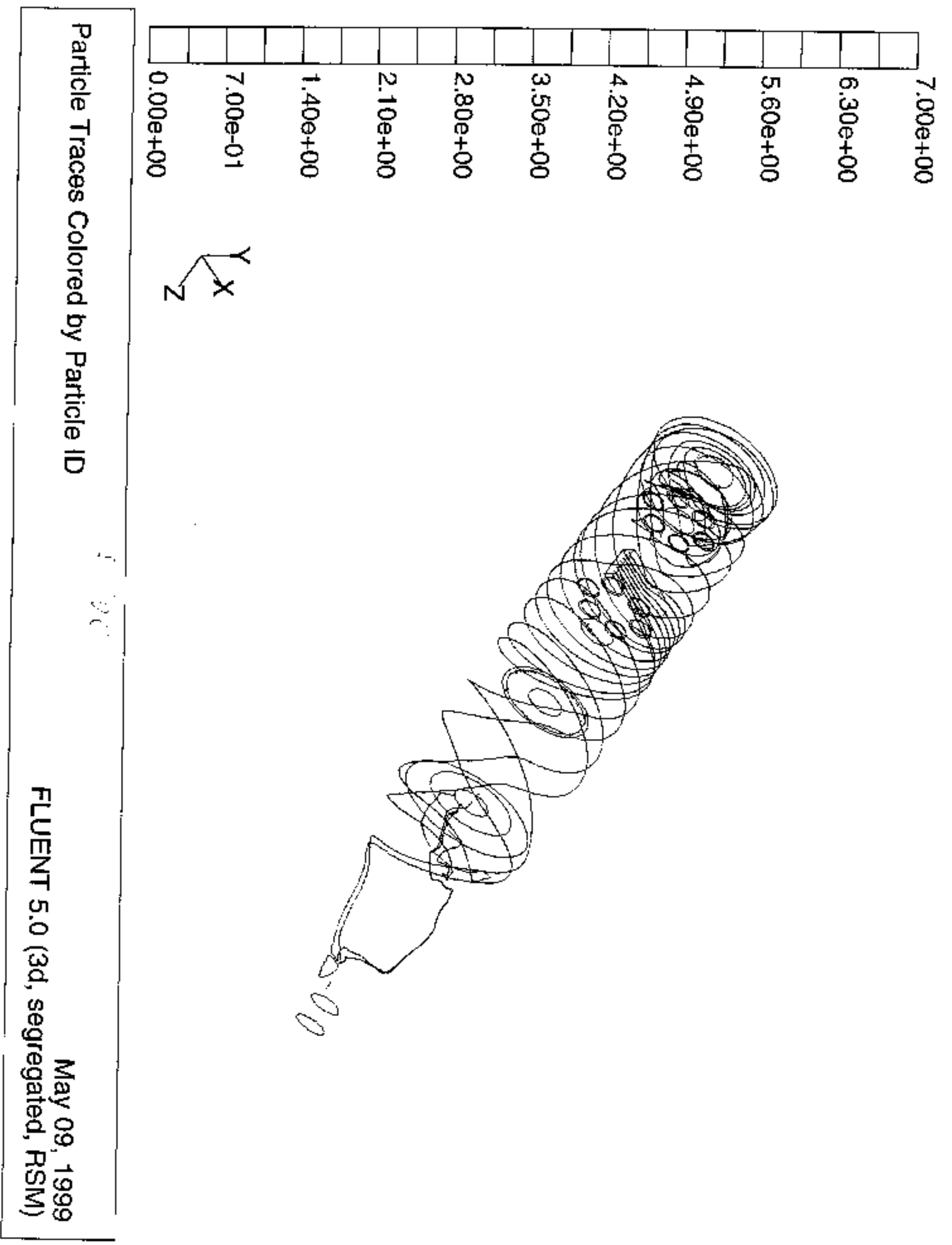




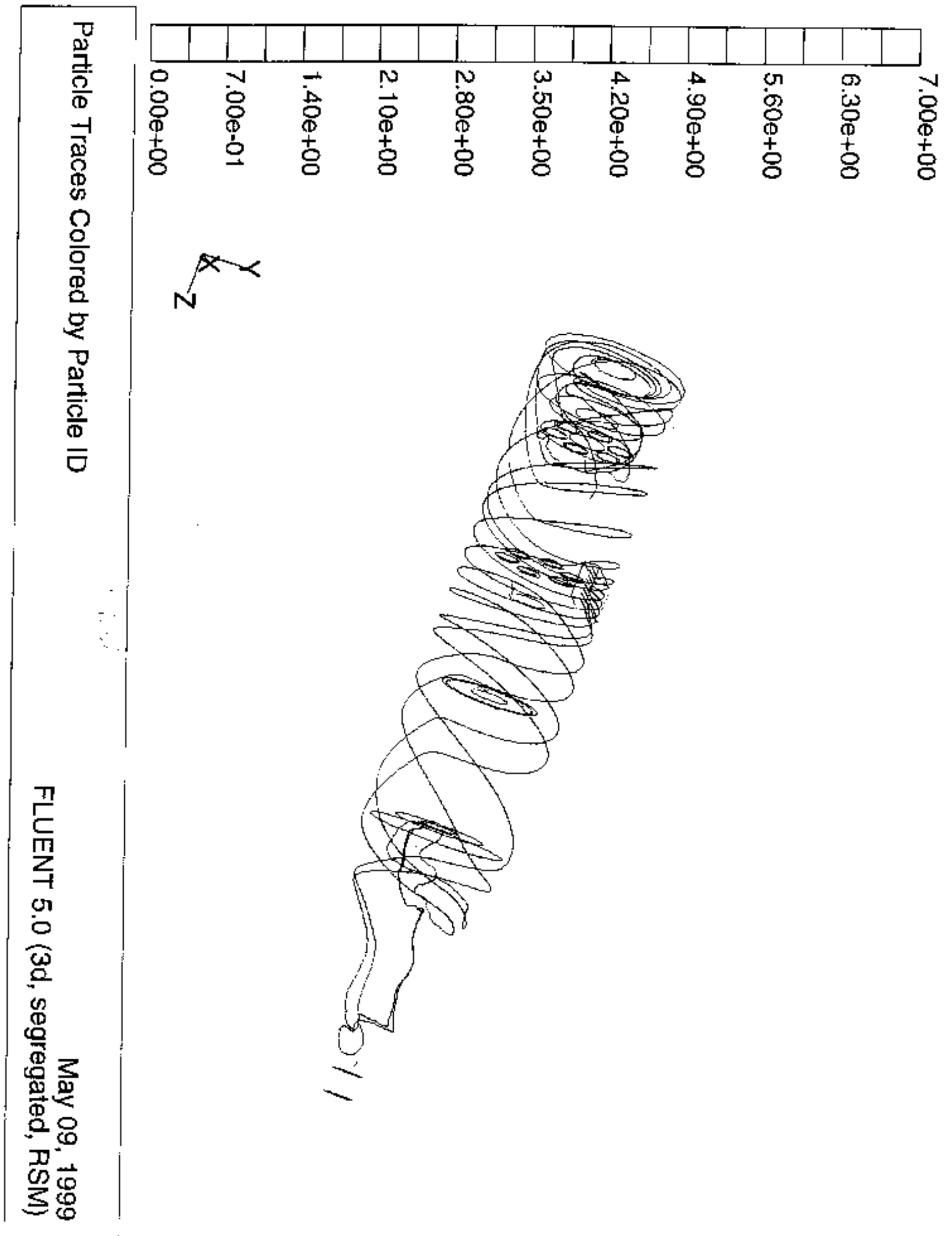




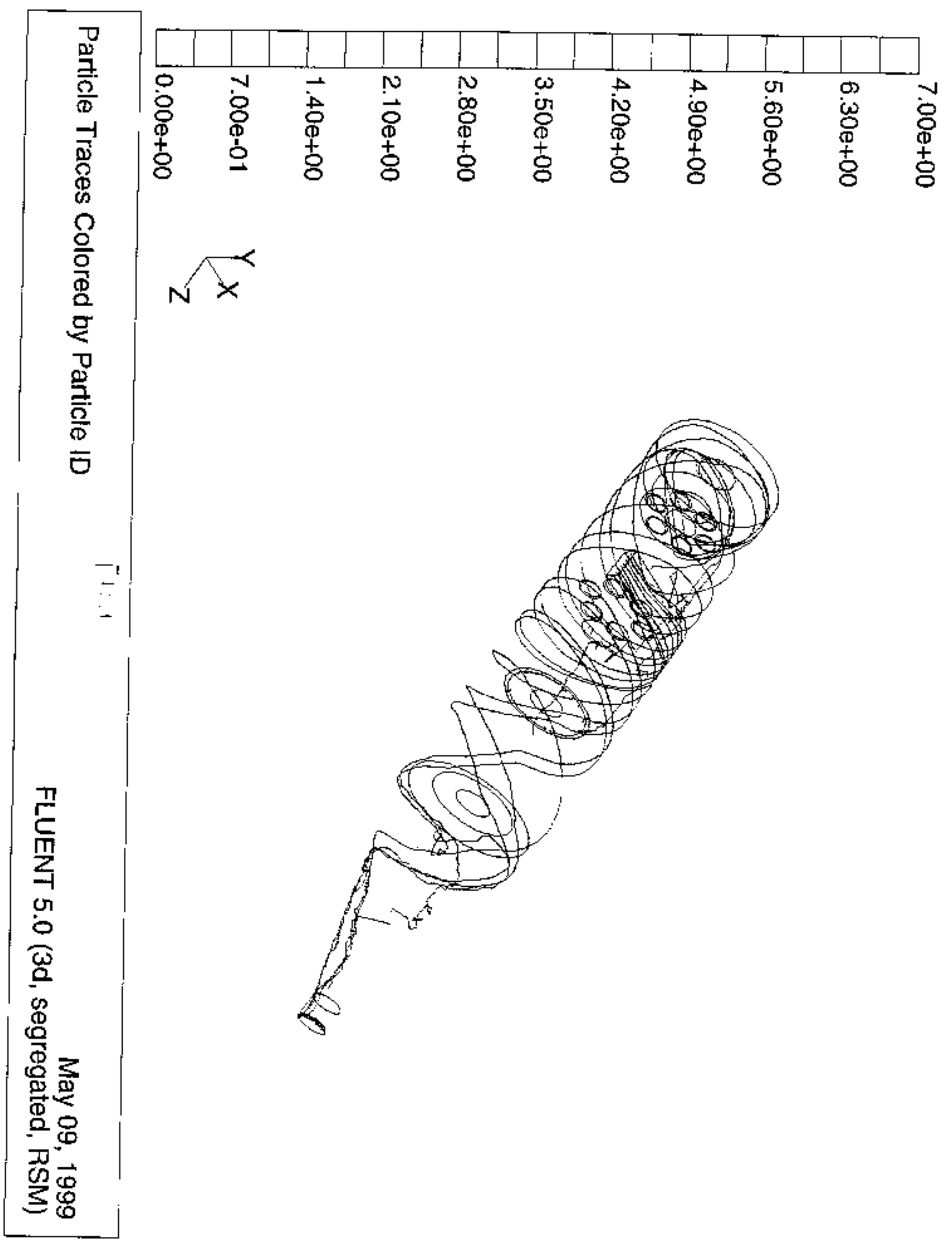




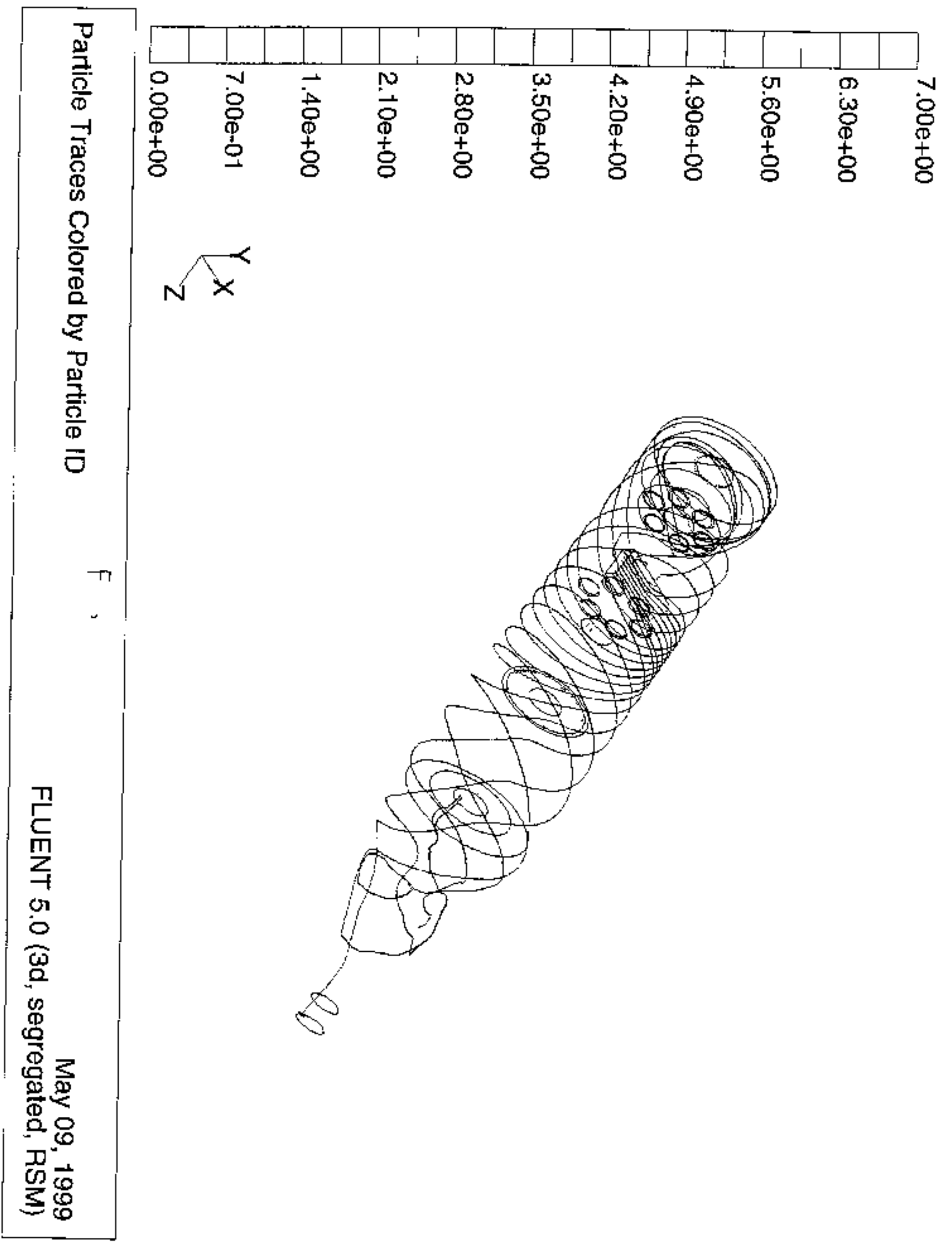




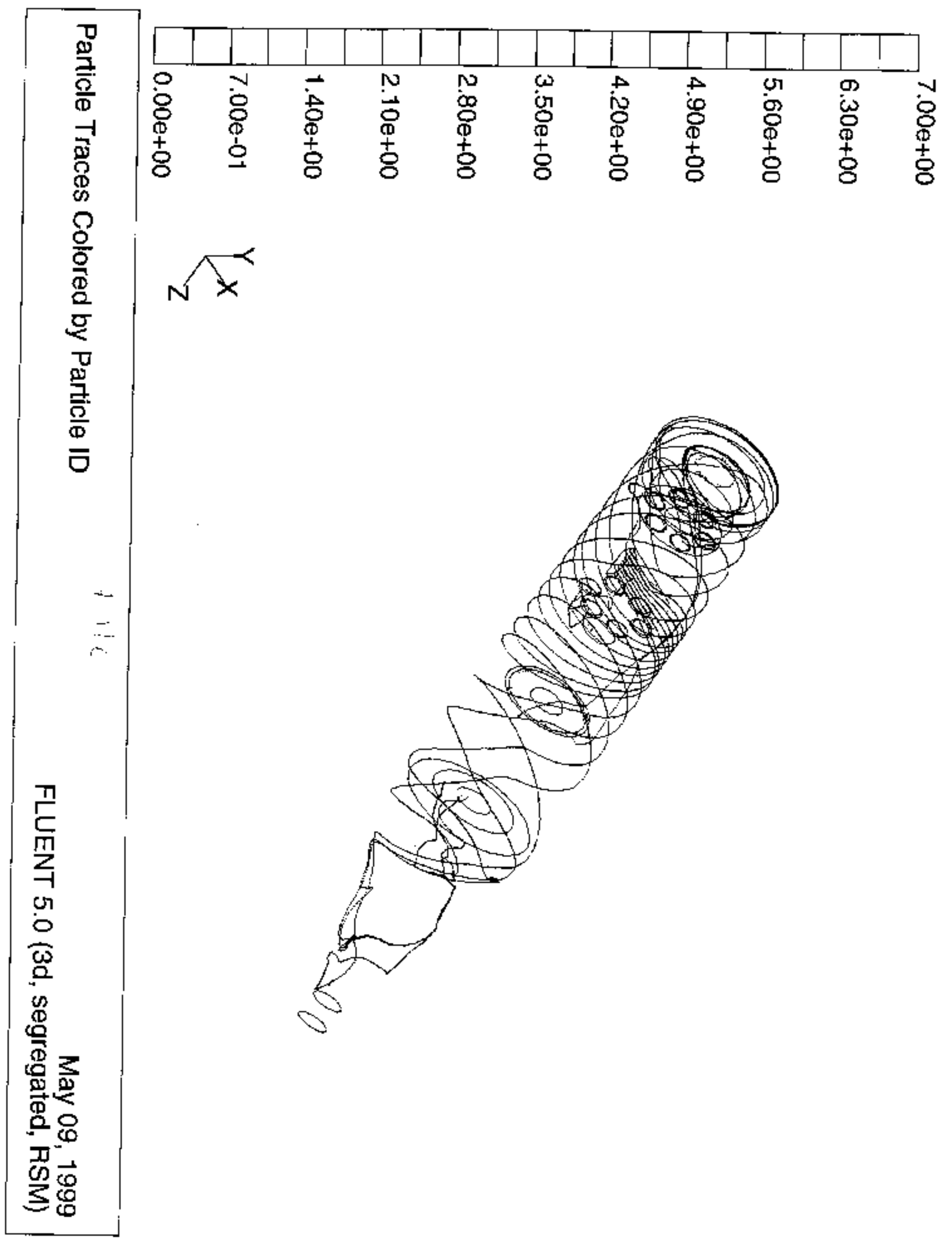




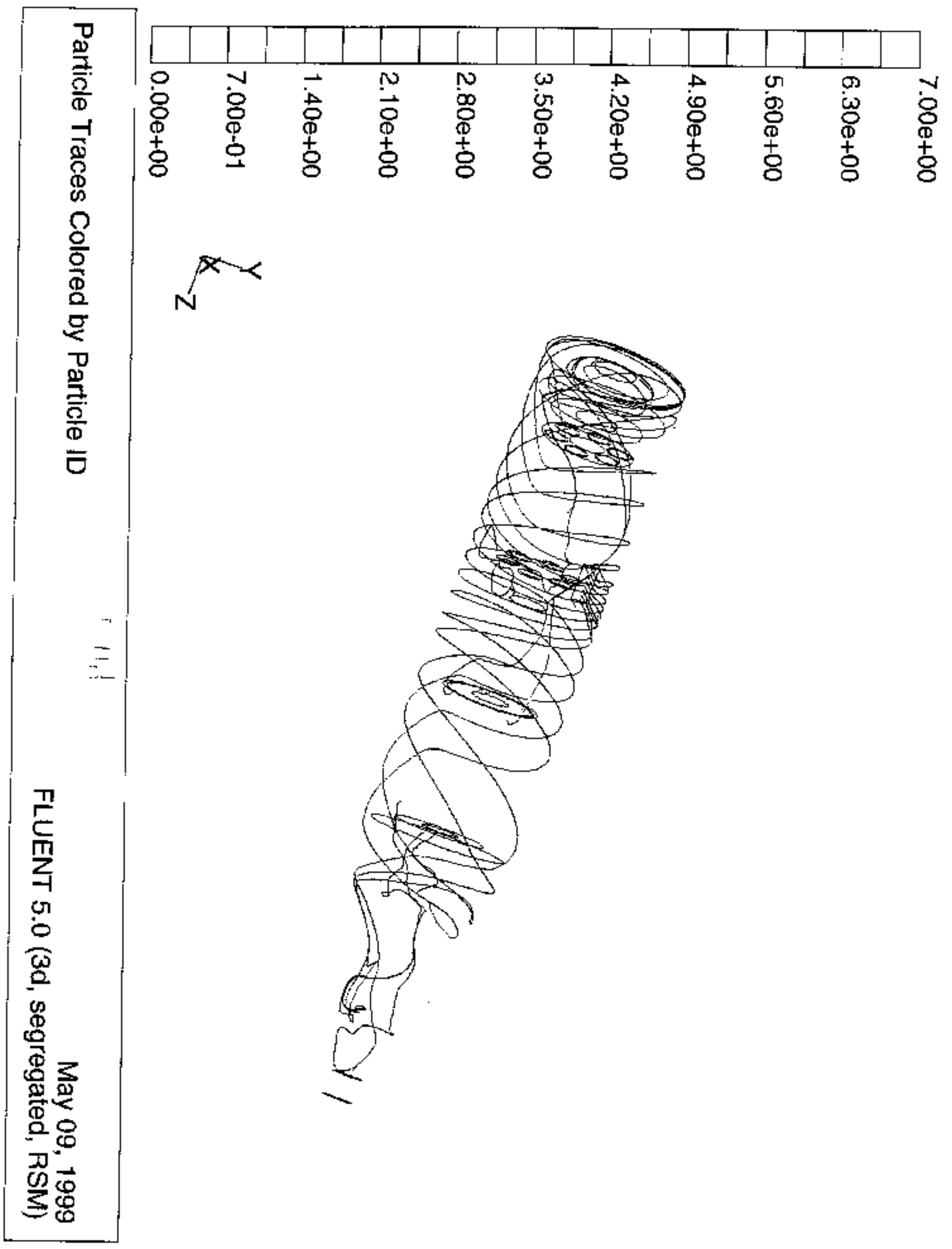




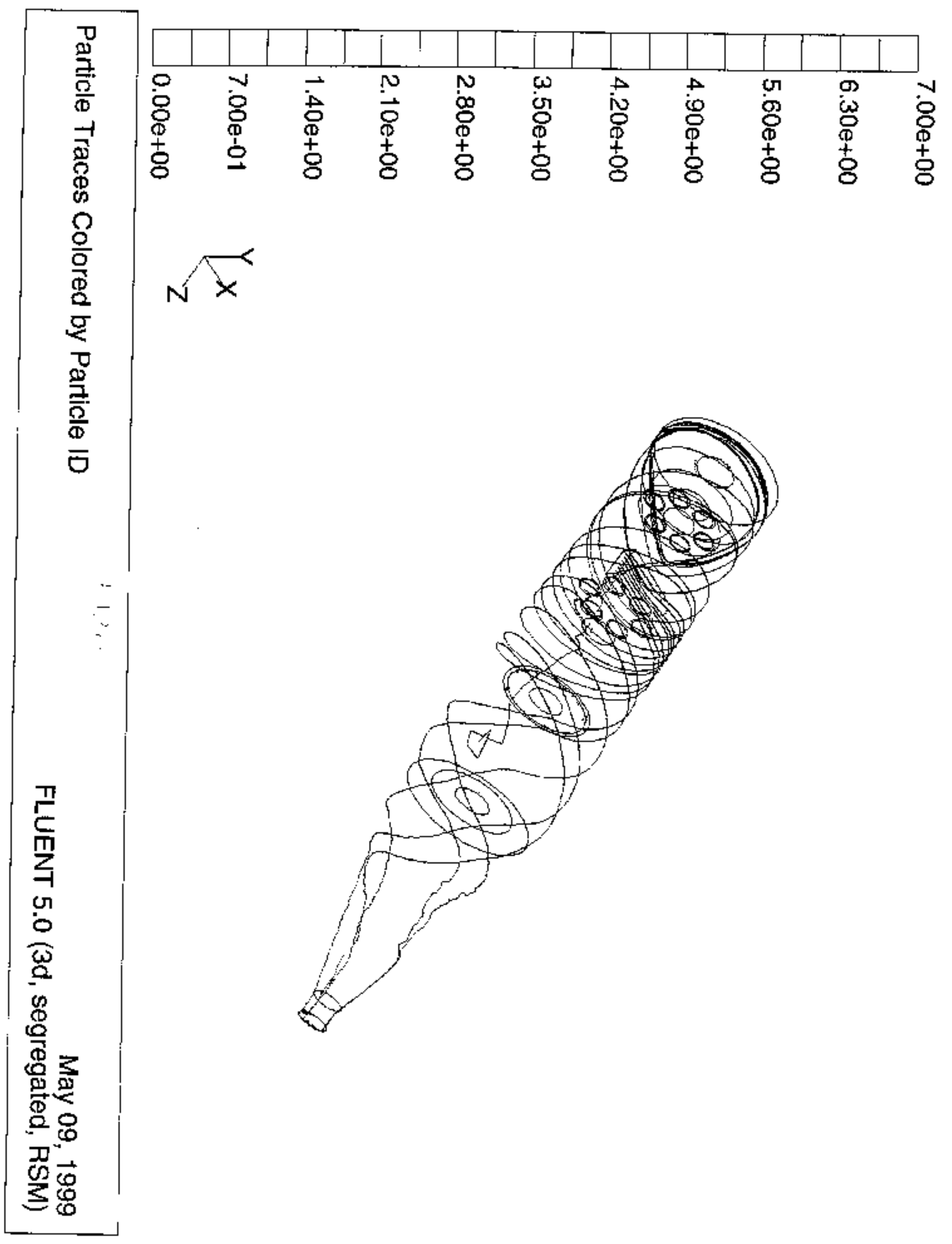




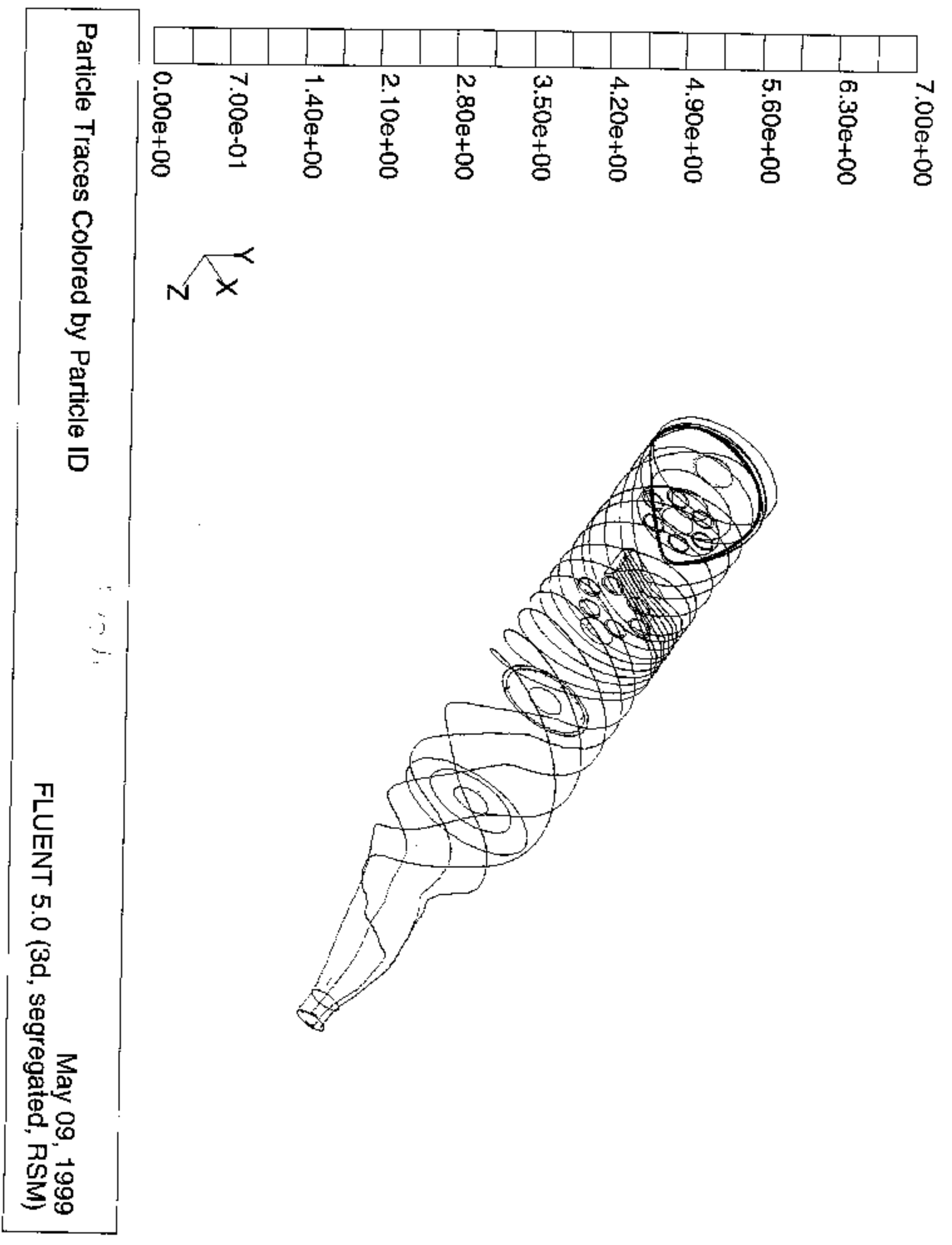




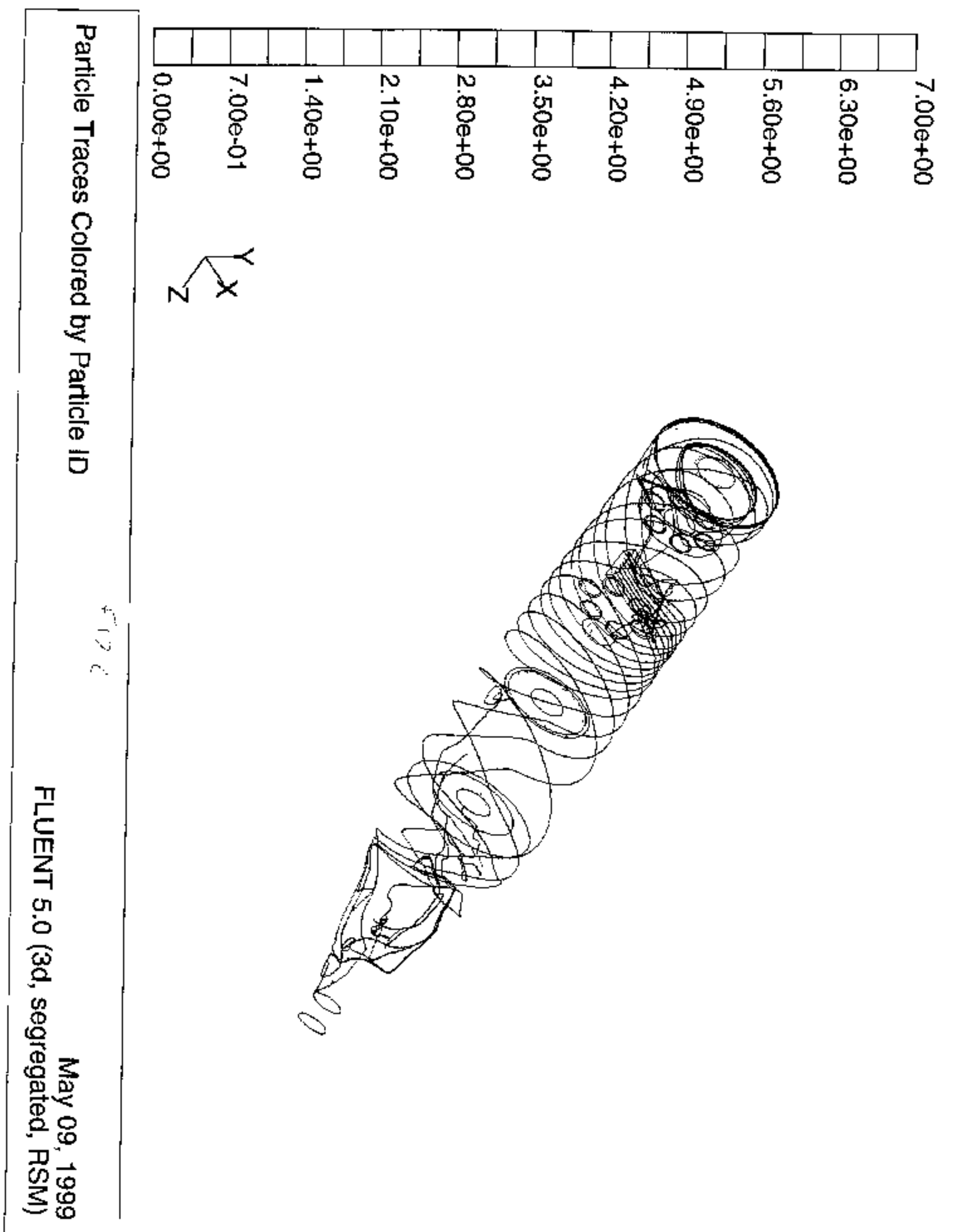




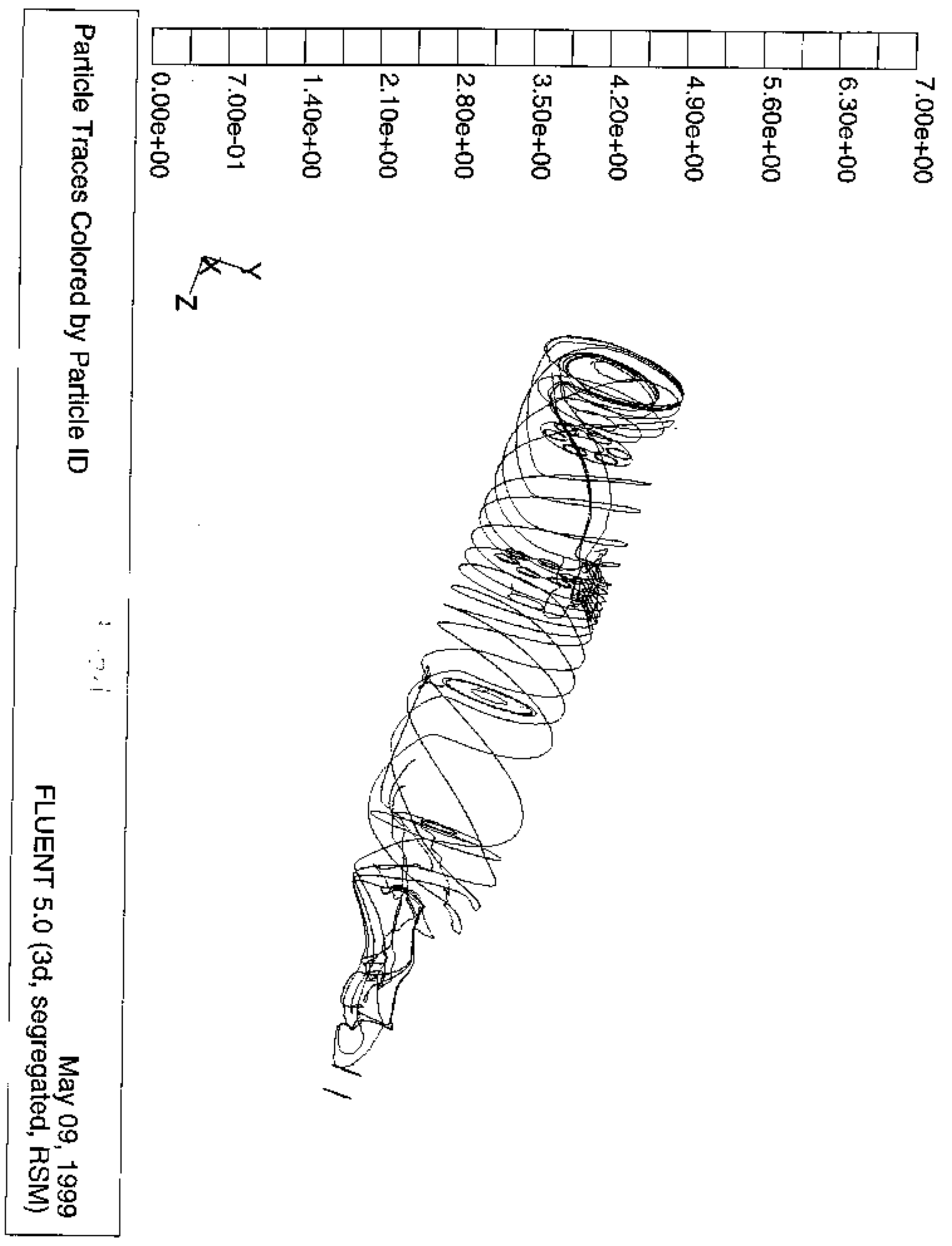

